\title{
Synthesis of NNN Chiral Ruthenium Complexes and their Cytotoxicity Studies.
}

Pran Gobinda Nandi, ${ }^{\ddagger a}$ Praveen Kumar Jadi,${ }^{\ddagger b}$ Kanu Das, ${ }^{a}$ Siriyara Jagannatha Prathapa, ${ }^{c}$ Biman B. Mandal ${ }^{* b, d}$ and Akshai Kumar* ${ }^{a, d}$

${ }^{a}$ Department of Chemistry, Indian Institute of Technology Guwahati, Guwahati - 781039, Assam, India

${ }^{b}$ Department of Bioscience and Bioengineering, Indian Institute of Technology Guwahati, Guwahati - 781039, Assam, India

'Bruker India Scientific Pvt. Ltd. Bengaluru-560092, Karnataka, India.

${ }^{d}$ Center for Nanotechnology, Indian Institute of Technology Guwahati, Guwahati - 781039, Assam, India

Table of Contents

\begin{tabular}{|l|l|l|}
\hline 1 & X-ray Analysis & 2 \\
\hline 2 & NMR and ESI-MS Spectra & 4 \\
\hline 3 & UV-Vis spectra & 14 \\
\hline 4 & Cyclic voltammetry & 16 \\
\hline 5 & CD spectra & 18 \\
\hline 6 & ESI-MS Spectra in the presence of DMSO & 20 \\
\hline 7 & Fluorescence studies of the complexes in presence of DMSO & 23 \\
\hline
\end{tabular}




\section{X-ray Analysis}

Justification of alerts observed in the check_cif file of $\left({ }^{\mathrm{RR}-\mathrm{MeBu} 2} \mathrm{NNN}\right) \mathrm{RuCl}_{2}\left(\mathrm{PPh}_{3}\right)_{3}$

\section{Alert level A}

\section{RINTA01 ALERT 3 A The value of Rint is greater than 0.25 Rint given 0.293}

Author response: The data quality is poor due to sensitive and unstable nature of crystal that decreased the crystal quality. Crystals diffracted extremely weakly and disintegrated during the data collection. Multiple attempts were made to grow better diffracting crystals, however, upon mounting, all yielded serious problems due to high instability of crystal. This resulted in weak diffraction and disorder in the solvent atom positions. These factors resulted in high Rint value.

PLAT020 ALERT 3 A The Value of Rint is greater than 0.12

0.293 Report

Author response: The data quality is poor due to sensitive and unstable nature of crystal that decreased the crystal quality. Crystals diffracted extremely weakly and disintegrated during the data collection. Multiple attempts were made to grow better diffracting crystals, however, upon mounting, all yielded serious problems due to high instability of crystal. This resulted in weak diffraction and disorder in the solvent atom positions. These factors resulted in high Rint value.

\section{Alert level B}

PLAT242 ALERT 2 B Low 'MainMol' Ueq as Compared to Neighbors of C1B Check

Author response: ISOR restraints were applied to some of the atoms to avoid atoms becoming flat /Non positive definite's due to poor quality data. Some of these atoms are still not ideally shaped, however, this does not indicate an incorrect atom-type assignment.

PLAT342 ALERT 3 B Low Bond Precision on C-C Bonds 0.02984 Ang.

Author response: Extremely poor-quality crystal owing to its unstable nature resulted in observation of streaky diffused Bragg peaks giving poor data, overall poor model and hence low bond precision. However, this does not indicate an incorrect atom type assignment. 
.Table S1: The crystallographic data of 1c

\begin{tabular}{|c|c|}
\hline Name & $\left({ }^{\mathrm{R} 2} \mathrm{NNN}\right) \mathrm{RuCl} 2\left(\mathrm{PPh}_{3}\right)(\mathbf{1 c})$ \\
\hline Empirical formula & $\mathrm{C}_{35} \mathrm{H}_{42} \mathrm{Cl}_{2} \mathrm{~N}_{3} \mathrm{PRu}$ \\
\hline Formula weight & 707.65 \\
\hline Crystal size $\left(\mathrm{mm}^{3}\right)$ & $0.32 \times 0.24 \times 0.22$ \\
\hline Crystal system & Monoclinic \\
\hline Space group & $\mathrm{P} 2_{1}$ \\
\hline $\mathrm{a}(\AA)$ & $19.9311(14)$ \\
\hline $\mathrm{b}(\AA)$ & $17.9214(13)$ \\
\hline $\mathrm{c}(\AA)$ & $32.457(2)$ \\
\hline$\alpha(\operatorname{deg})$ & 90 \\
\hline$\beta(\operatorname{deg})$ & $102.269(3)$ \\
\hline$\gamma(\mathrm{deg})$ & 90 \\
\hline $\mathrm{V}\left(\AA^{3}\right)$ & $11328.6(14)$ \\
\hline $\mathrm{Z}$ & 12 \\
\hline$\rho_{\text {calc }}\left(\mathrm{g} \mathrm{cm}^{-3}\right)$ & 1.245 \\
\hline$\mu\left(\mathrm{M}_{0} \mathrm{~K} \alpha\right)\left(\mathrm{mm}^{-1}\right)$ & 0.624 \\
\hline$F(000)$ & 4392.0 \\
\hline $\mathrm{T}(\mathrm{K})$ & $296(2)$ \\
\hline Range of indices $(\mathrm{h} ; \mathrm{k} ; \mathrm{l})$ & $-23 \leq \mathrm{h} \leq 24,-21 \leq \mathrm{k} \leq 21,-39 \leq 1 \leq 39$ \\
\hline Number of reflections collected & 457176 \\
\hline Unique reflection & 41737 \\
\hline Completeness to $2 \theta$ & 1.284 to 51.038 \\
\hline $\mathrm{R}_{\text {int }}$ & 0.2933 \\
\hline Data / restraints / parameters & $41737 / 115 / 2305$ \\
\hline goodness-of-fit & 1.008 \\
\hline $\mathrm{R}_{1}[I \geq 2 \sigma(I)]$ & 0.0863 \\
\hline $\mathrm{wR}_{2}[I \geq 2 \sigma(I)]$ & 0.1607 \\
\hline $\mathrm{R}_{1}$ (all data) & 0.1551 \\
\hline$w_{2}$ (all data) & 0.1917 \\
\hline$\Delta_{\mathrm{r}}(\max , \min )$ e $\AA^{-3}$ & $0.55 /-0.53$ \\
\hline Flack parameter & $-0.01(3)$ \\
\hline
\end{tabular}


Table S2: Selected bond distances $(\AA)$ and angles $\left(^{\circ}\right)$ for the complex 1c

\begin{tabular}{ll}
\hline & $\left({ }^{\mathrm{R} 2} \mathrm{NNN}\right) \mathrm{Ru}\left(\mathrm{PPh}_{3}\right)(\mathbf{1 c})$ \\
\hline $\mathrm{Ru}-\mathrm{N}($ pyridine $)$ & $1.939(13)$ \\
\hline $\mathrm{Ru}-\mathrm{N}($ imine $)$ & $2.074(12)$ \\
& $2.110(13)$ \\
$\mathrm{Ru}-\mathrm{Cl}$ & $2.431(5)$ \\
& $2.466(5)$ \\
$\mathrm{Ru}-\mathrm{P}$ & $2.317(5)$ \\
$\mathrm{C}=\mathrm{N}(\mathrm{imine})$ & $1.30(2)$ \\
& $1.29(2)$ \\
\hline (im) $\mathrm{N}-\mathrm{Ru}-\mathrm{N}(\mathrm{im})$ & $157.0(6)$ \\
\hline $\mathrm{Cl}-\mathrm{Ru}-\mathrm{Cl}$ & $87.9(2)$ \\
\hline $\mathrm{P}-\mathrm{Ru}-\mathrm{Cl}$ (trans to $\left.\mathrm{PPh}_{3}\right)$ & $178.65(19)$ \\
\hline $\mathrm{P}-\mathrm{Ru}-\mathrm{Cl}$ (cis to $\left.\mathrm{PPh}_{3}\right)$ & $93.45(19)$ \\
\hline
\end{tabular}

\section{NMR and ESI-MS Spectra}

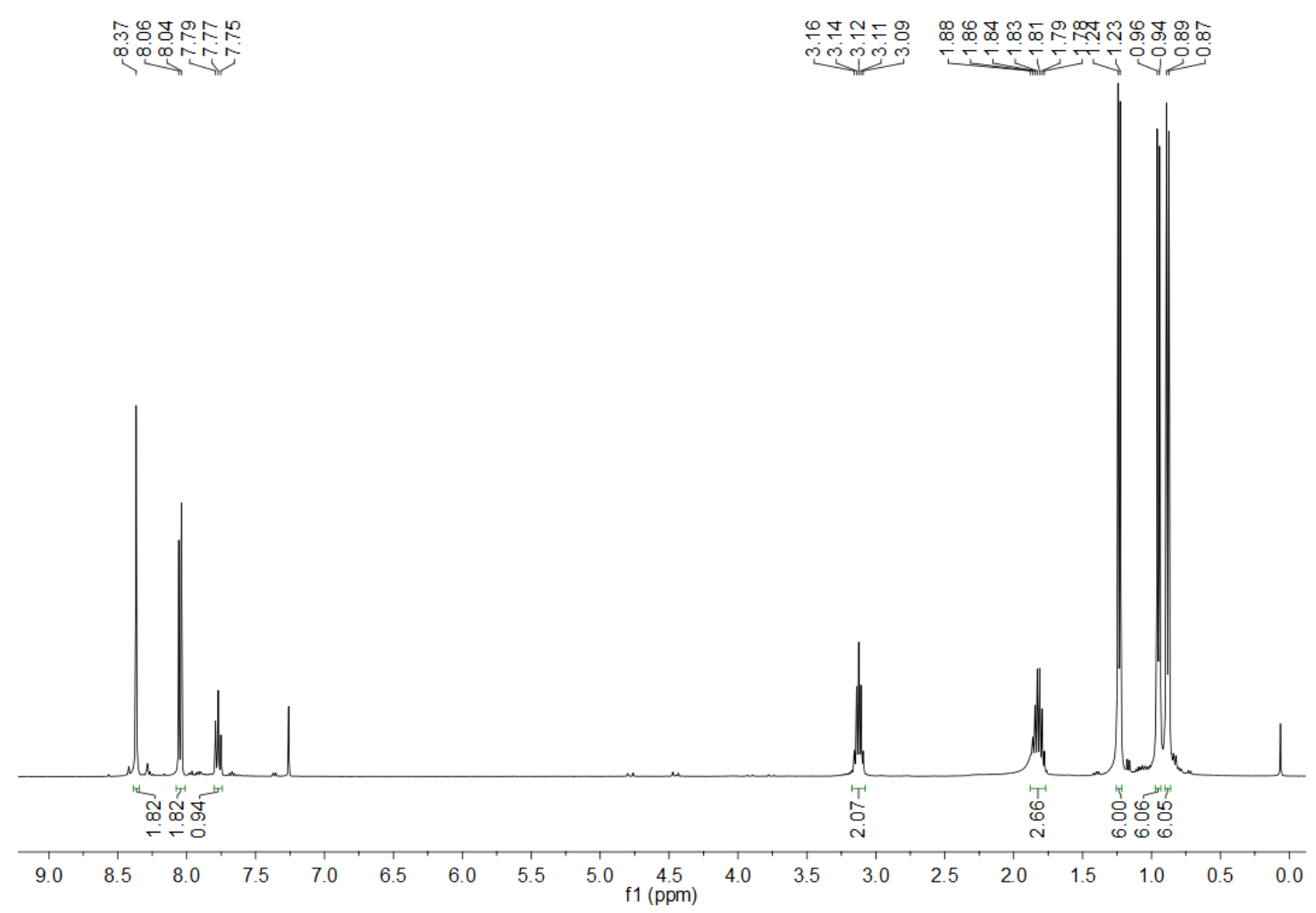

Figure S1: ${ }^{1} \mathrm{H}$ NMR Spectra of 4 in $\mathrm{CDCl}_{3}$ 


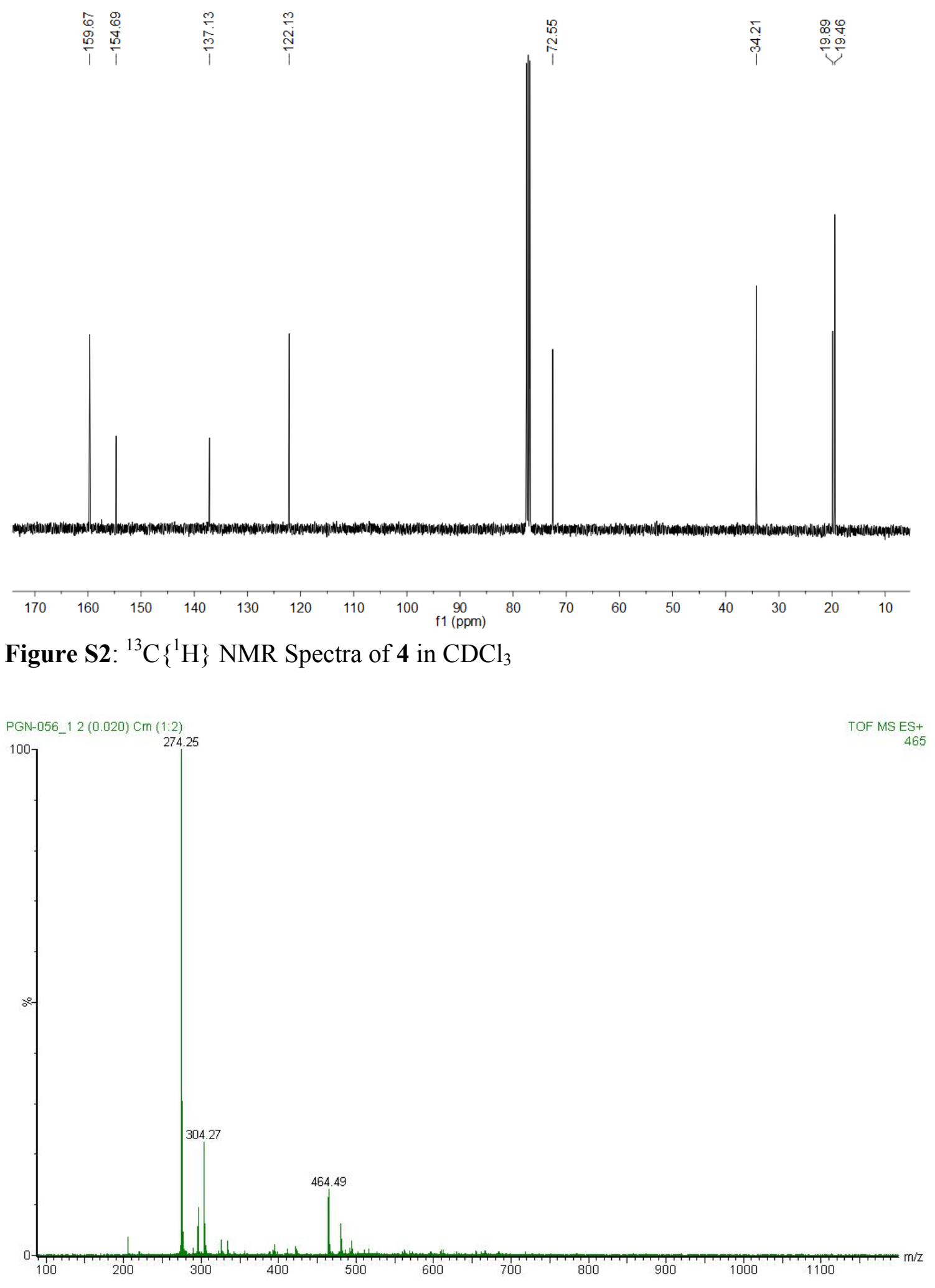

Figure S3: ESI-MS Spectra of 4 in $\mathrm{CH}_{3} \mathrm{OH}$ 


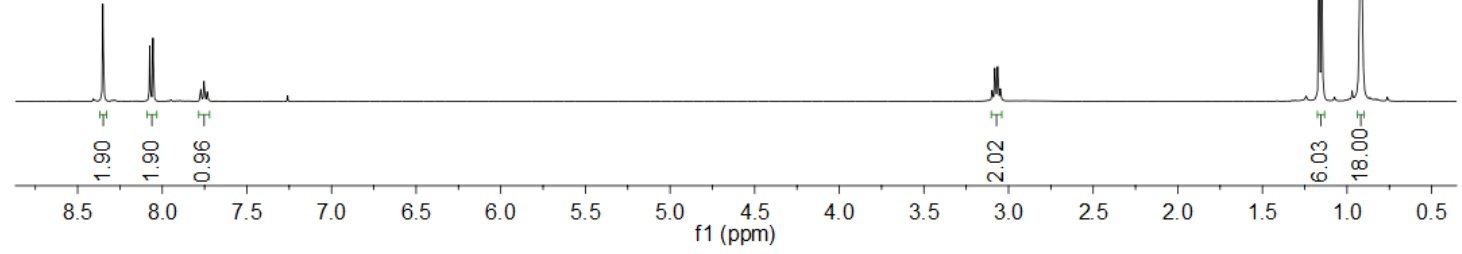

Figure S4: ${ }^{1} \mathrm{H}$ NMR Spectra of 6 in $\mathrm{CDCl}_{3}$

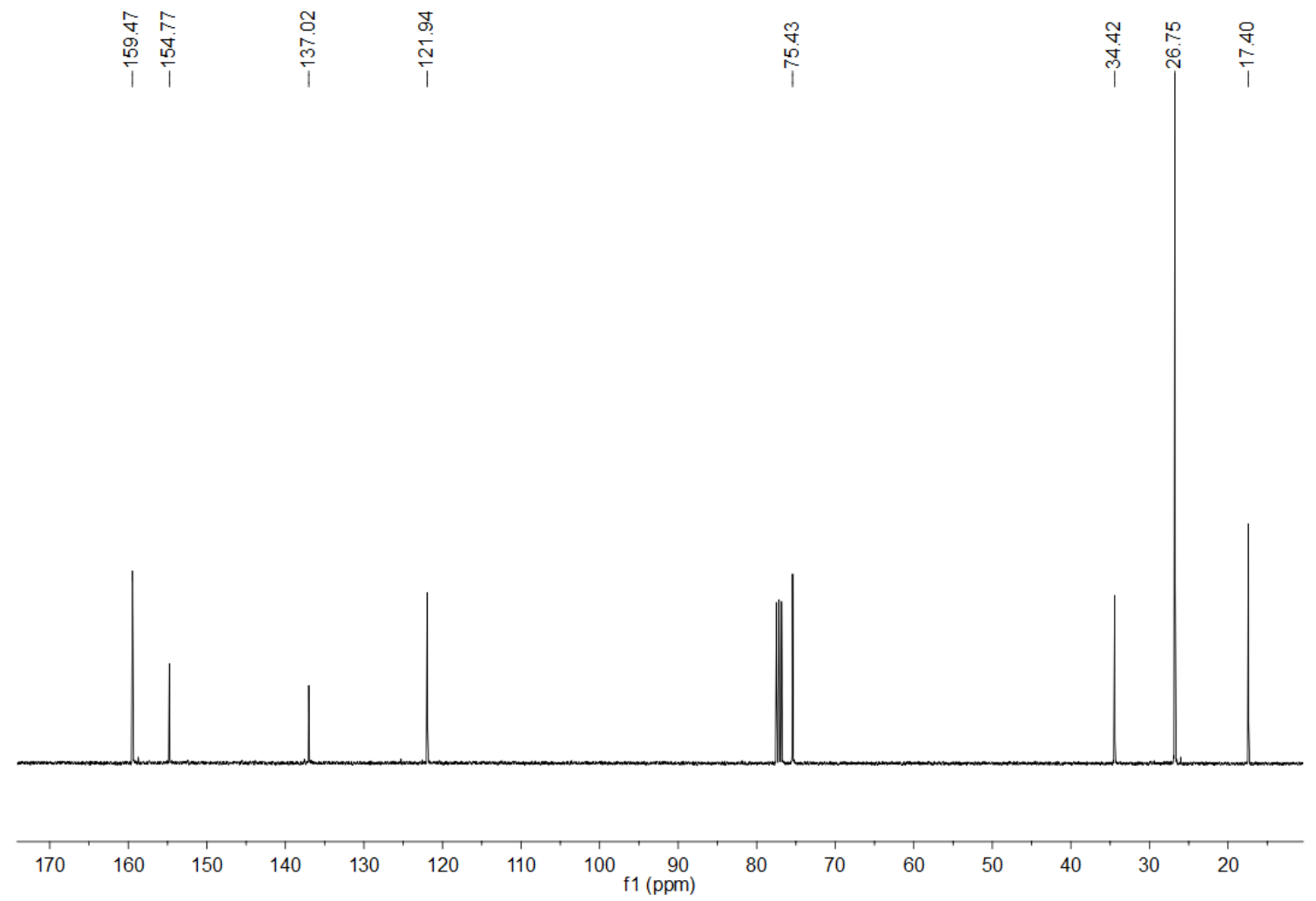

Figure S5: ${ }^{13} \mathrm{C}\left\{{ }^{1} \mathrm{H}\right\}$ NMR Spectra of 6 in $\mathrm{CDCl}_{3}$ 


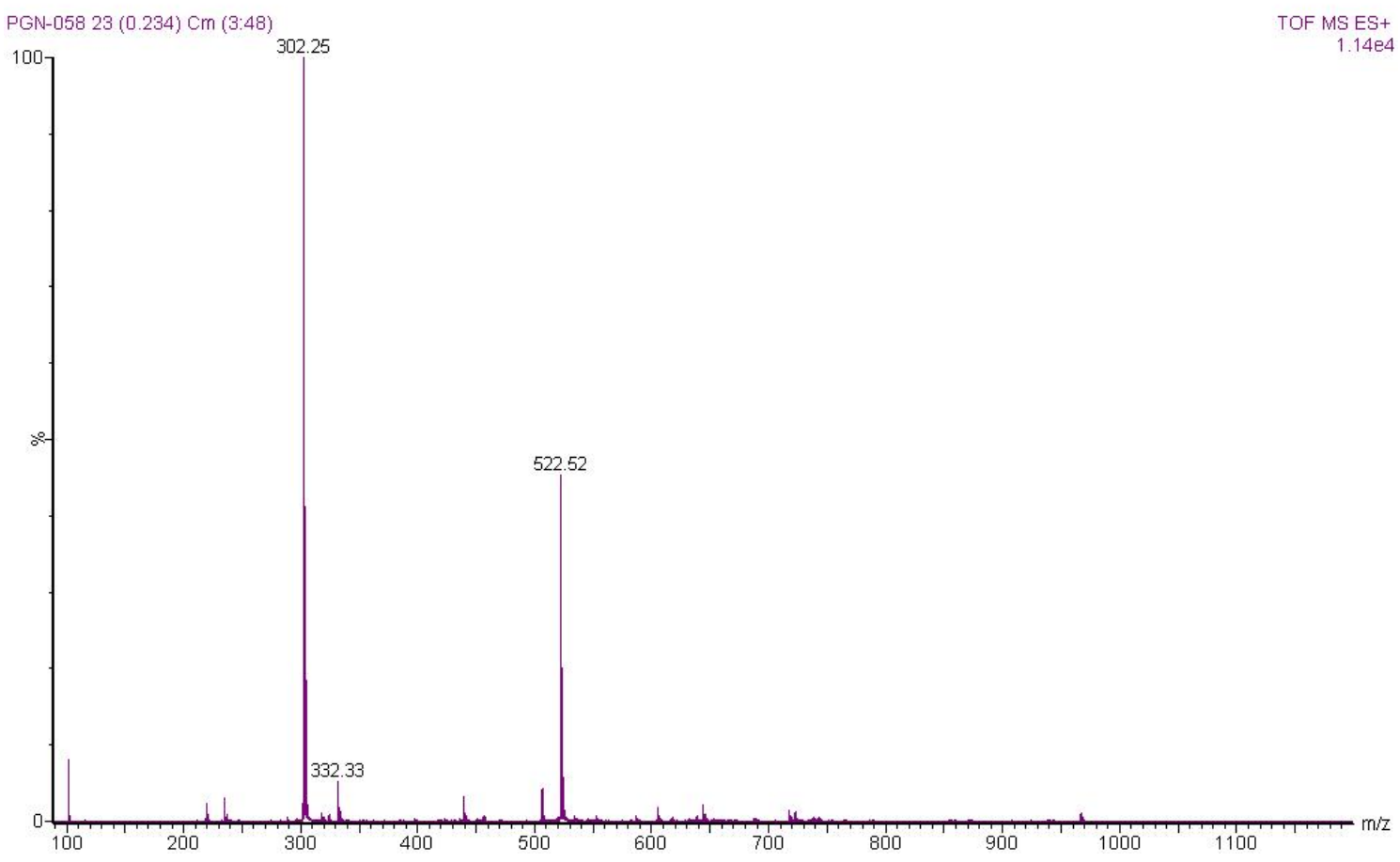

Figure S6: ESI-MS Spectra of 6 in $\mathrm{CH}_{3} \mathrm{OH}$

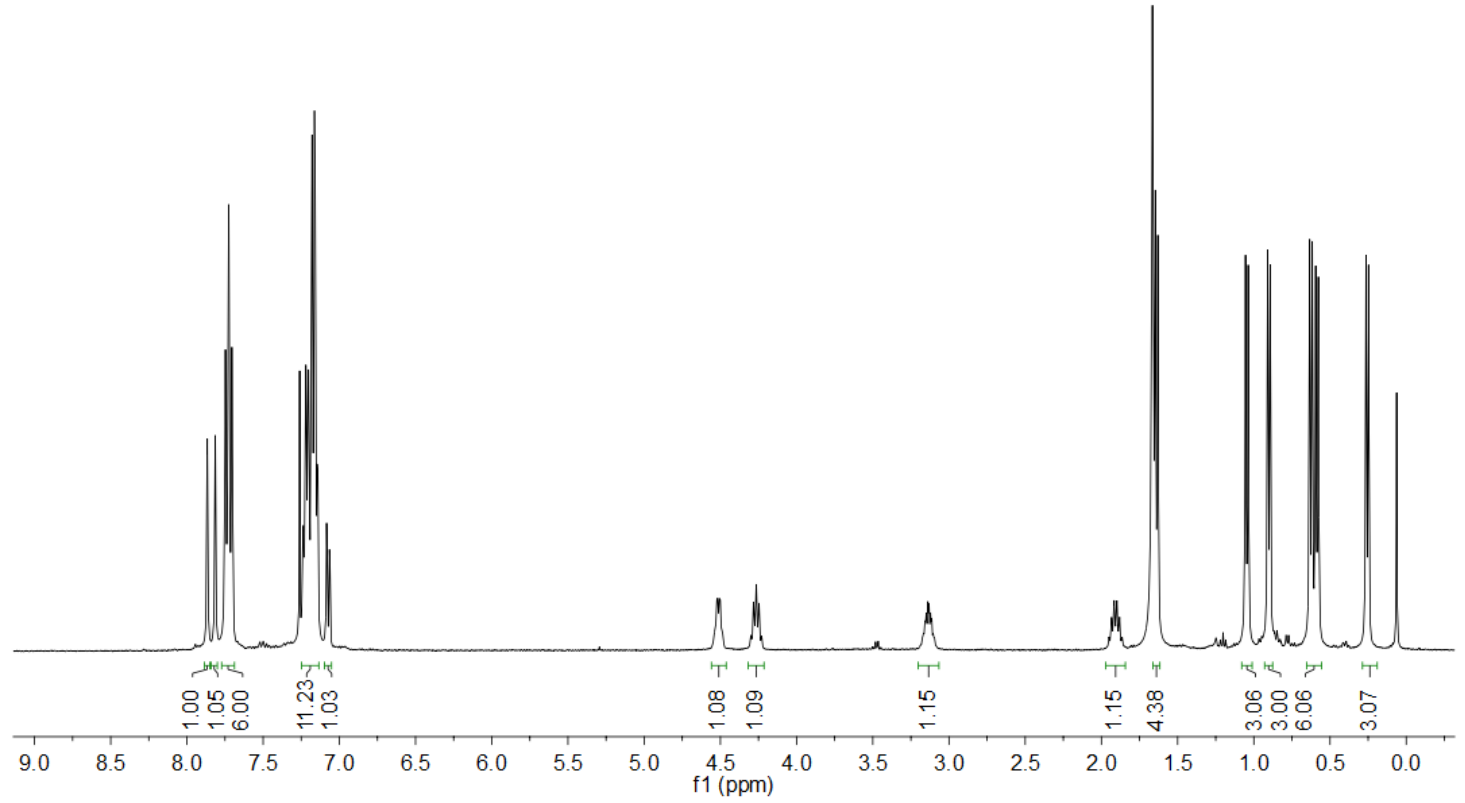

Figure S7: ${ }^{1} \mathrm{H}$ NMR Spectra of $1 \mathrm{c}$ in $\mathrm{CDCl}_{3}$ 

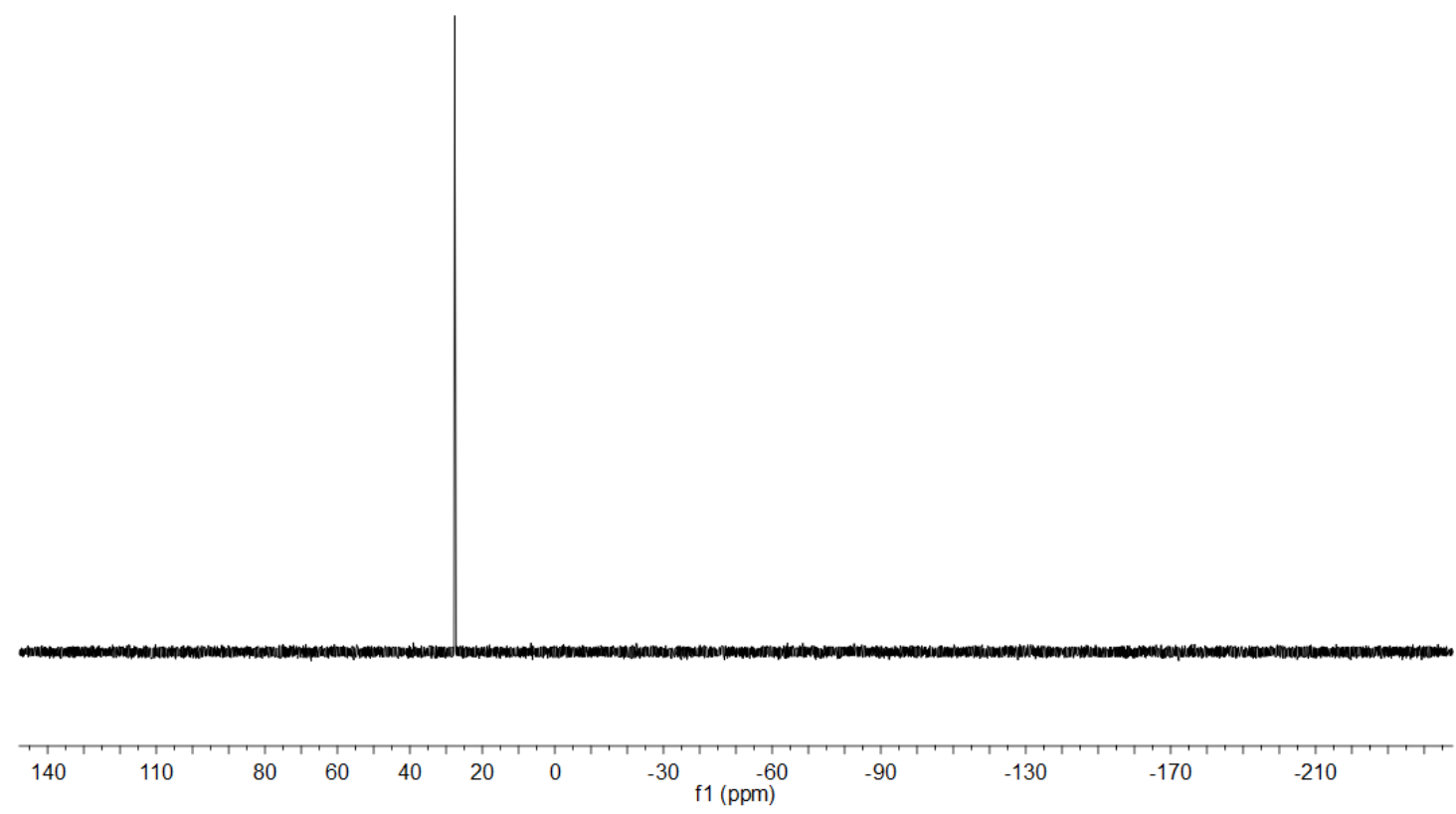

Figure S8: ${ }^{31} \mathrm{P}\left\{{ }^{1} \mathrm{H}\right\}$ NMR Spectra of $\mathbf{1 c}$ in $\mathrm{CDCl}_{3}$

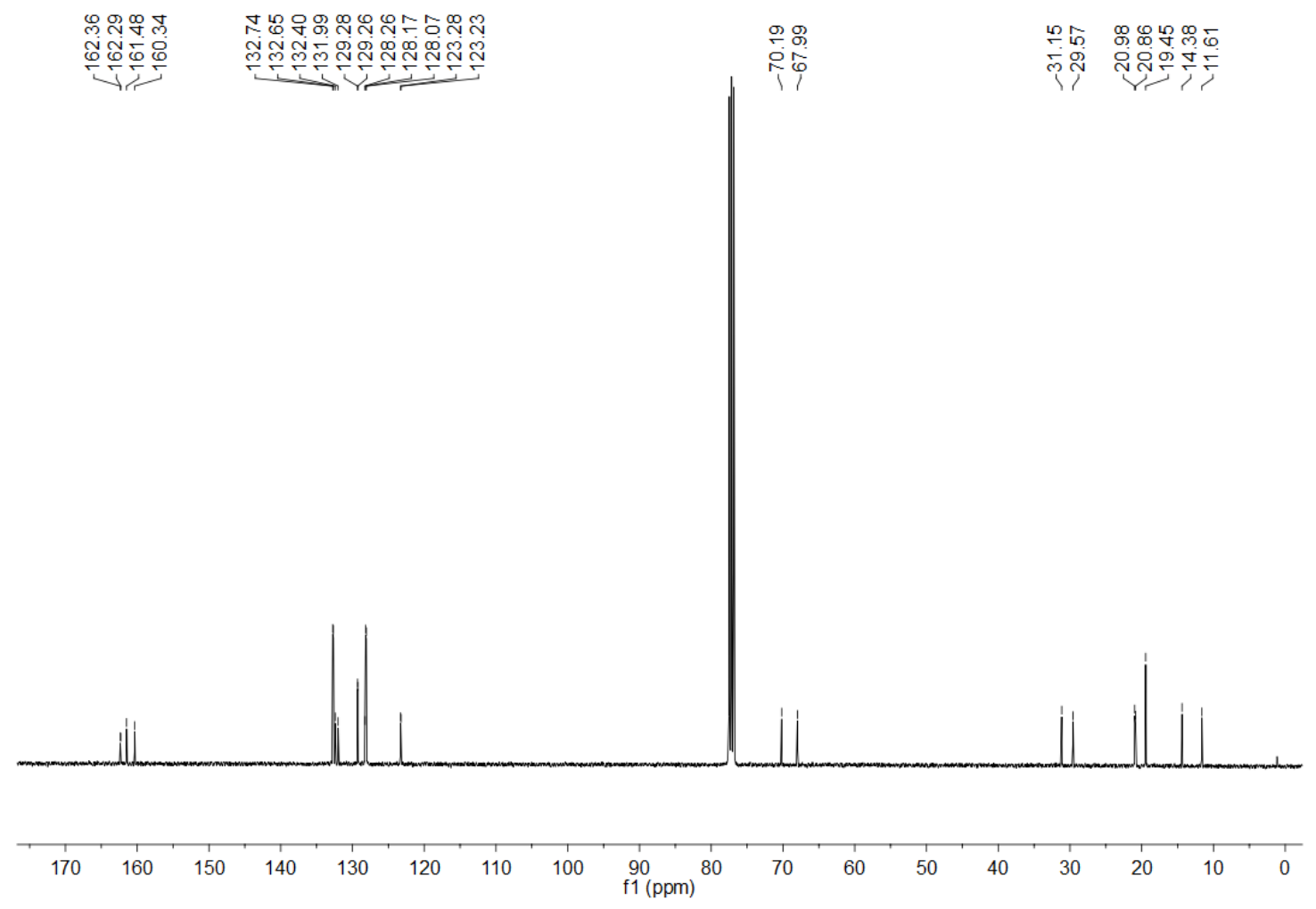

Figure S9: ${ }^{13} \mathrm{C}\left\{{ }^{1} \mathrm{H}\right\}$ NMR Spectra of $\mathbf{1 c}$ in $\mathrm{CDCl}_{3}$ 


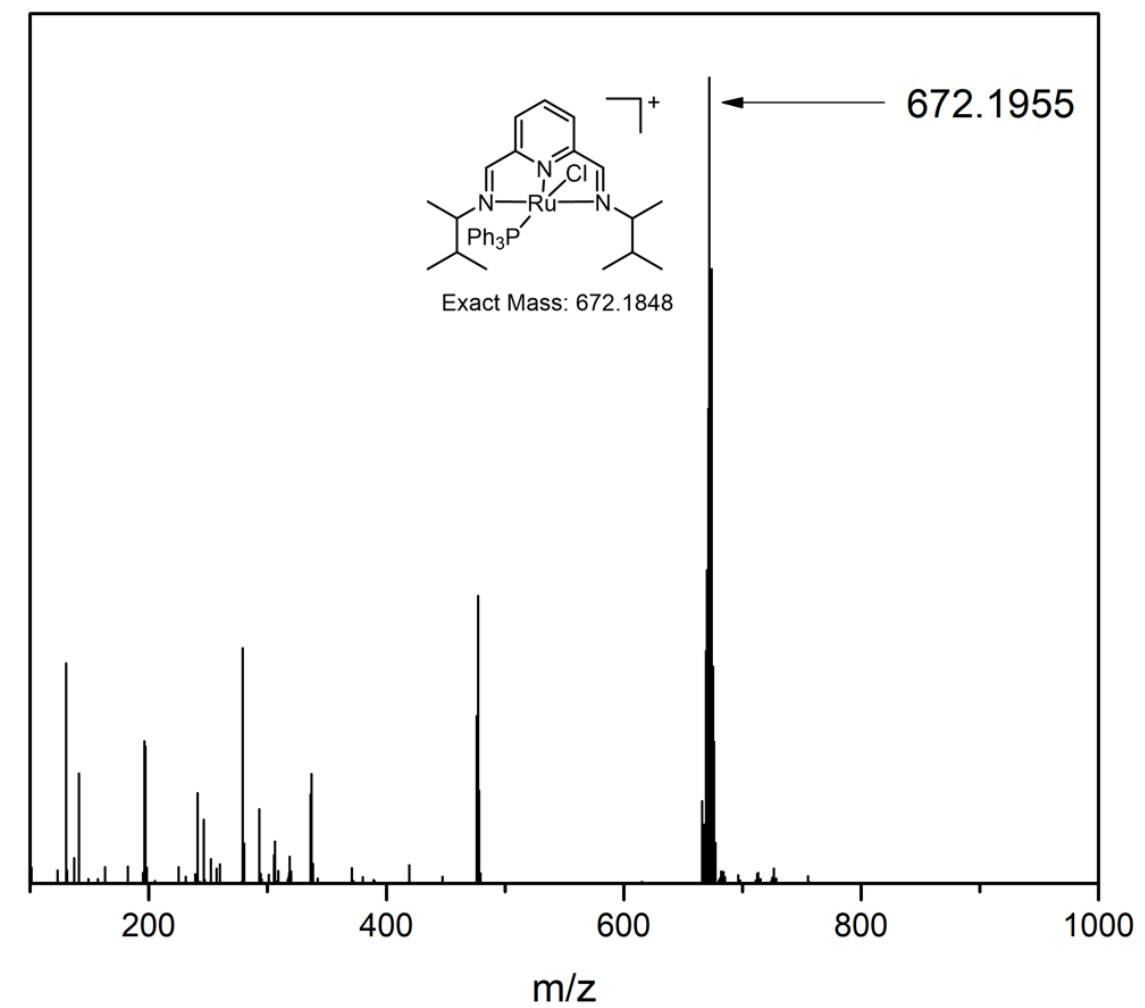

Figure S10: ESI-MS Spectra of $1 \mathrm{c}$ in $\mathrm{CH}_{3} \mathrm{OH}$

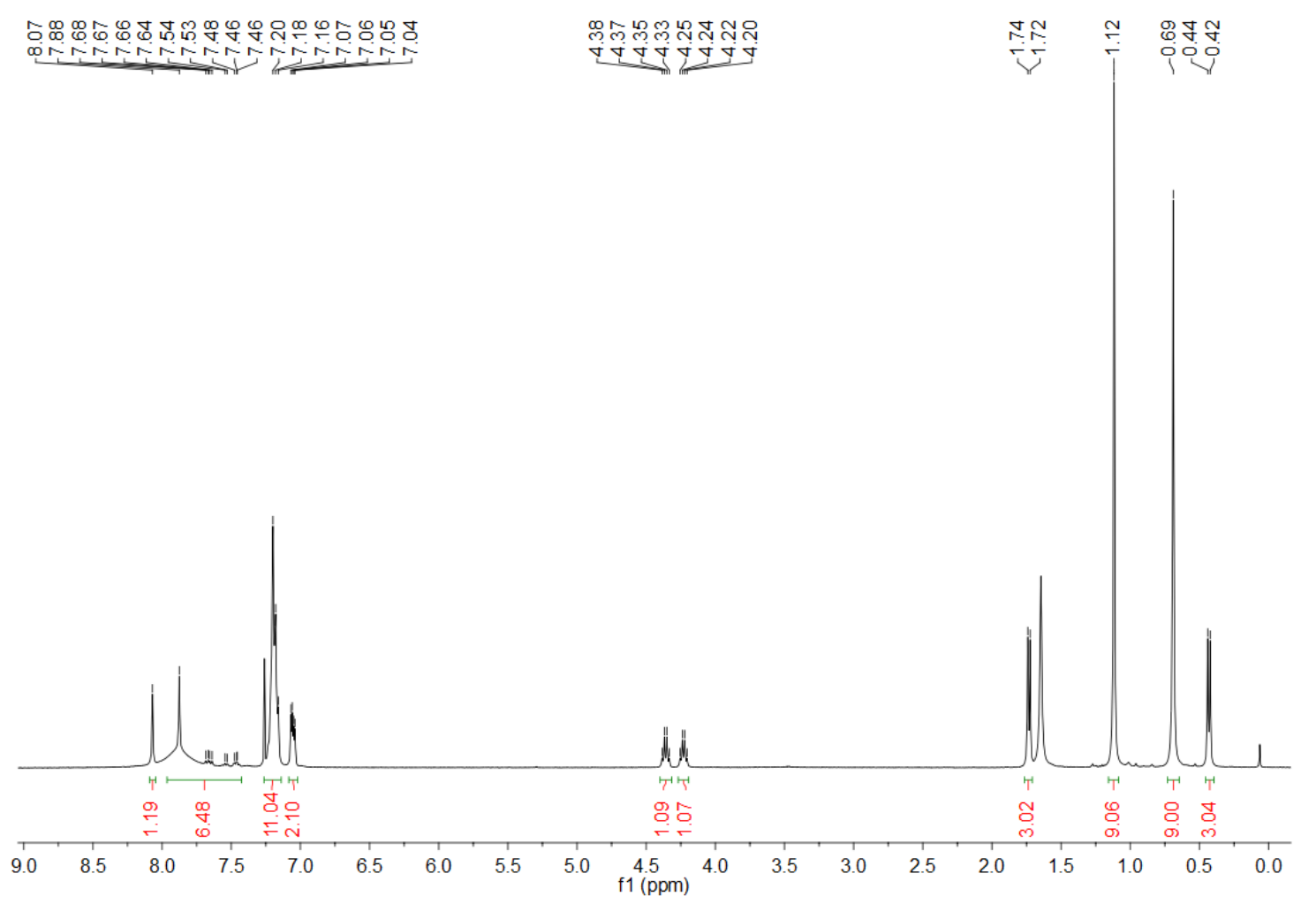

Figure S11: ${ }^{1} \mathrm{H}$ NMR Spectra of $\mathbf{1 d}$ in $\mathrm{CDCl}_{3}$ 


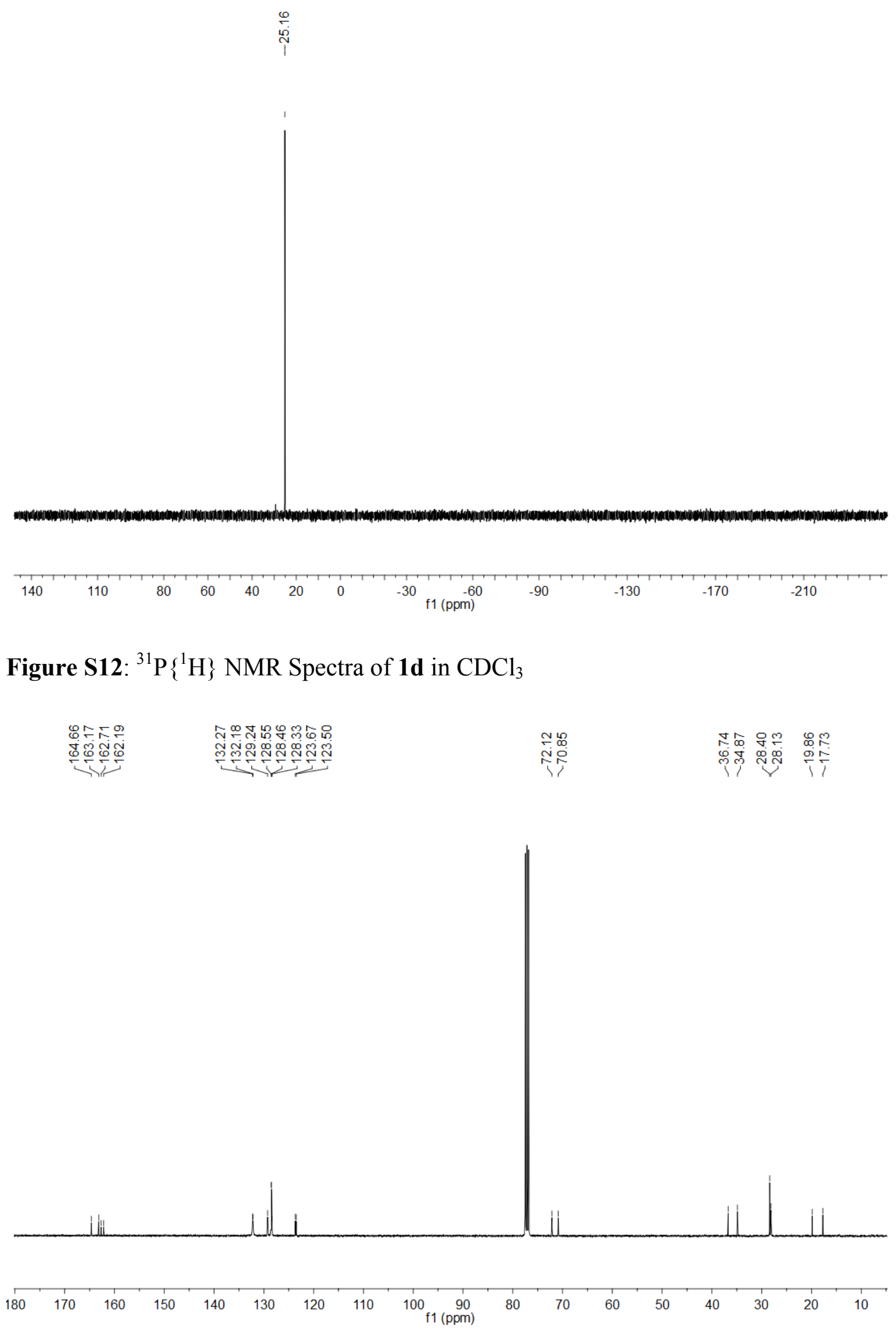

Figure S13: ${ }^{13} \mathrm{C}\left\{{ }^{1} \mathrm{H}\right\}$ NMR Spectra of 1d in $\mathrm{CDCl}_{3}$ 


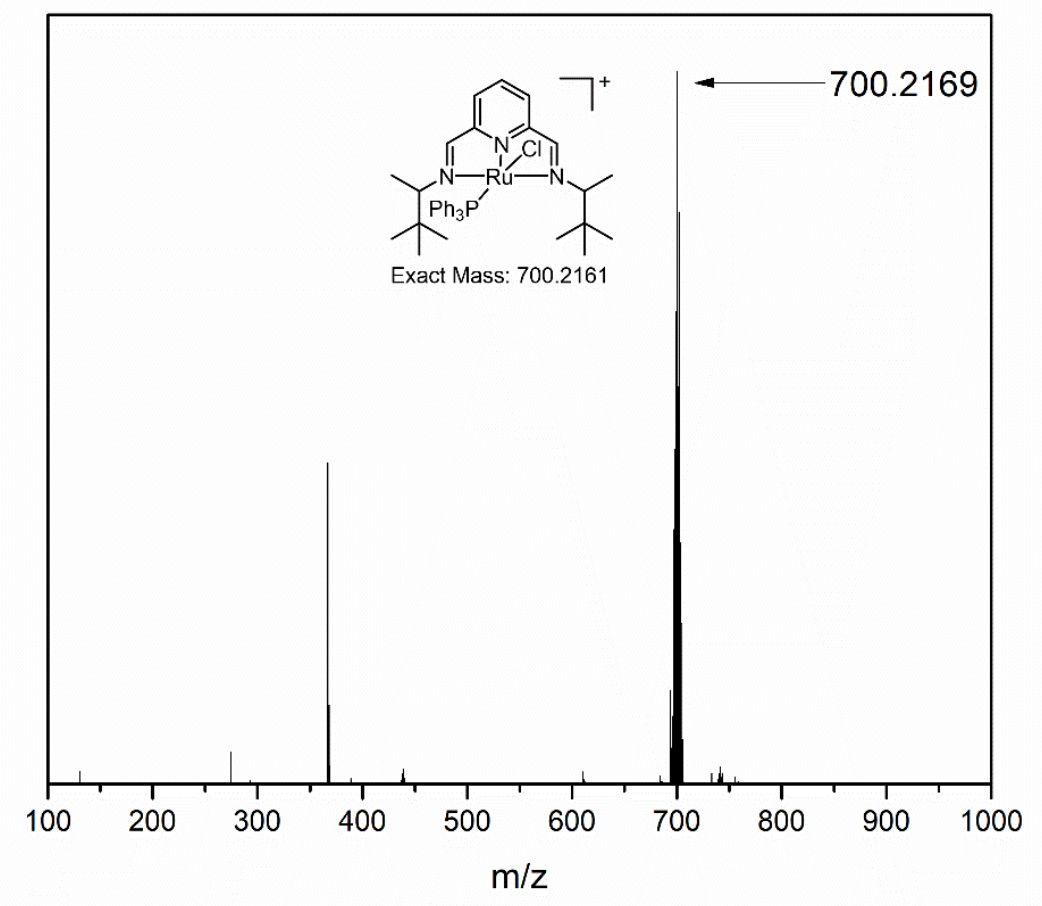

Figure S14: ESI-MS Spectra of $1 d$ in $\mathrm{CH}_{3} \mathrm{OH}$

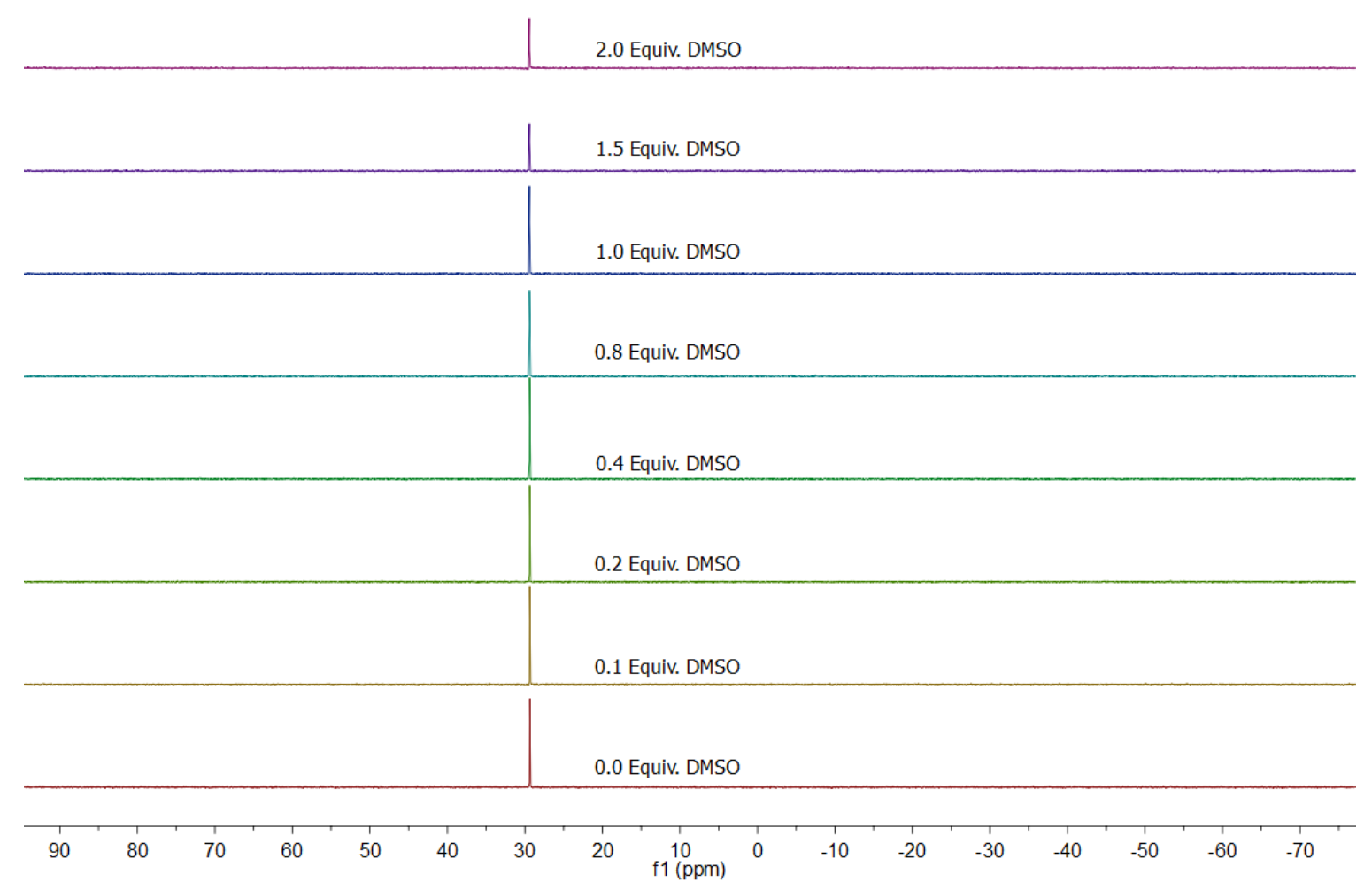

Figure S15: ${ }^{31} \mathrm{P}\left\{{ }^{1} \mathrm{H}\right\}$ NMR stacked plot of $\mathbf{1 a}$ in $\mathrm{CDCl}_{3}$ with adding various amount of DMSO 


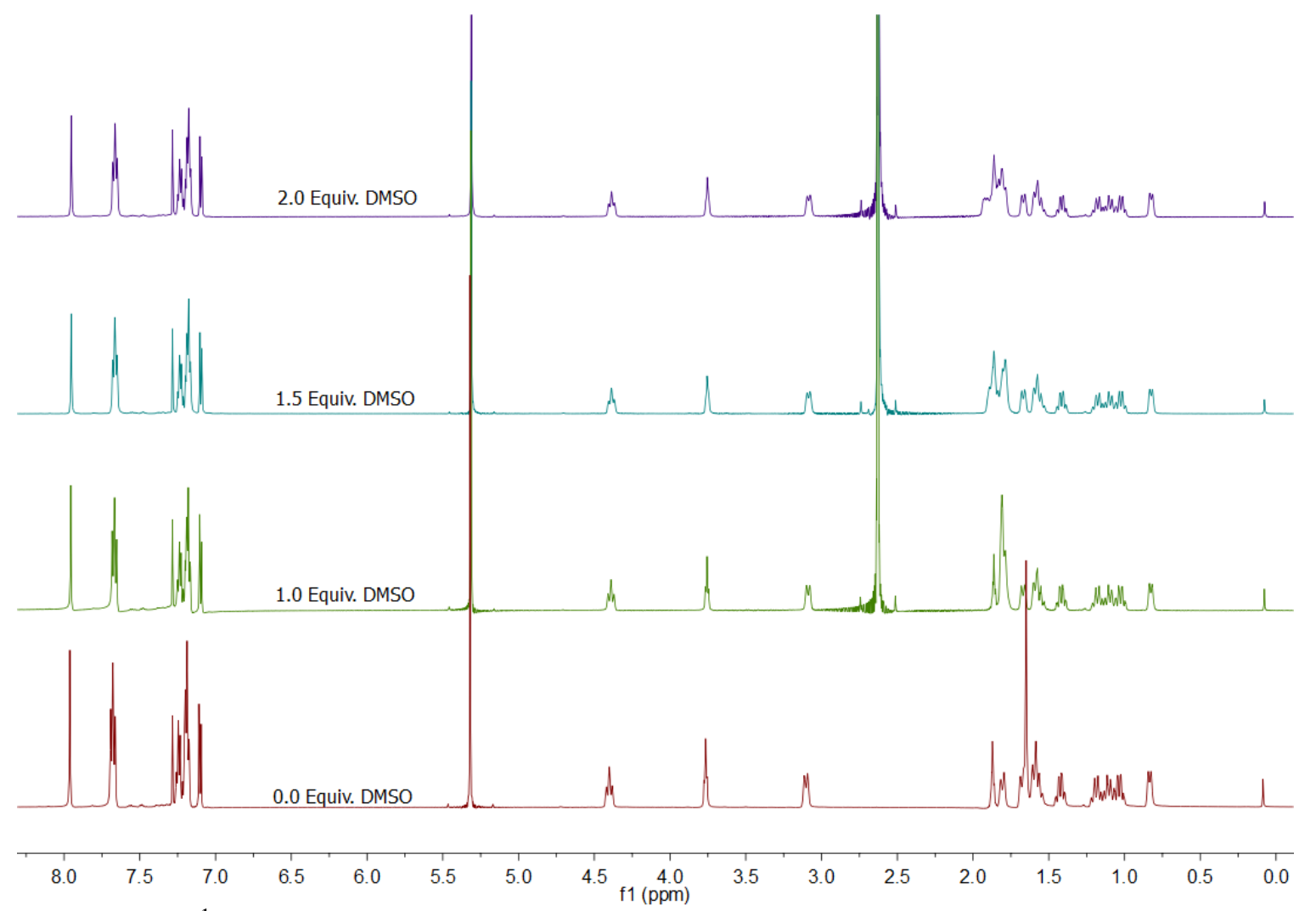

Figure S16: ${ }^{1} \mathrm{H}$ NMR stacked plot of $1 \mathbf{a}$ in $\mathrm{CDCl}_{3}$ with adding various amount of DMSO

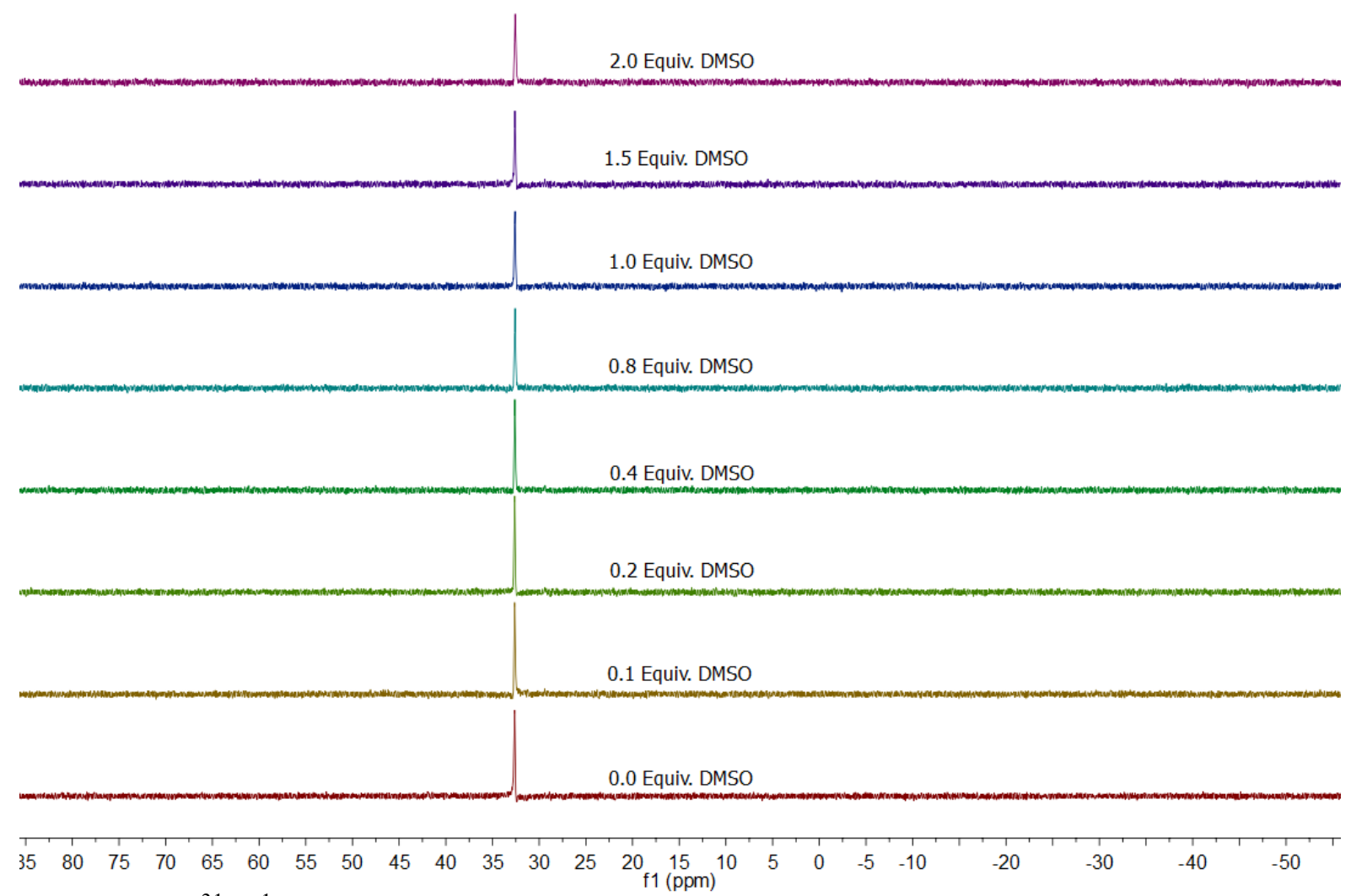

Figure S17: ${ }^{31} \mathrm{P}\left\{{ }^{1} \mathrm{H}\right\}$ NMR stacked plot of $\mathbf{1 b}$ in $\mathrm{CDCl}_{3}$ with adding various amount of DMSO 


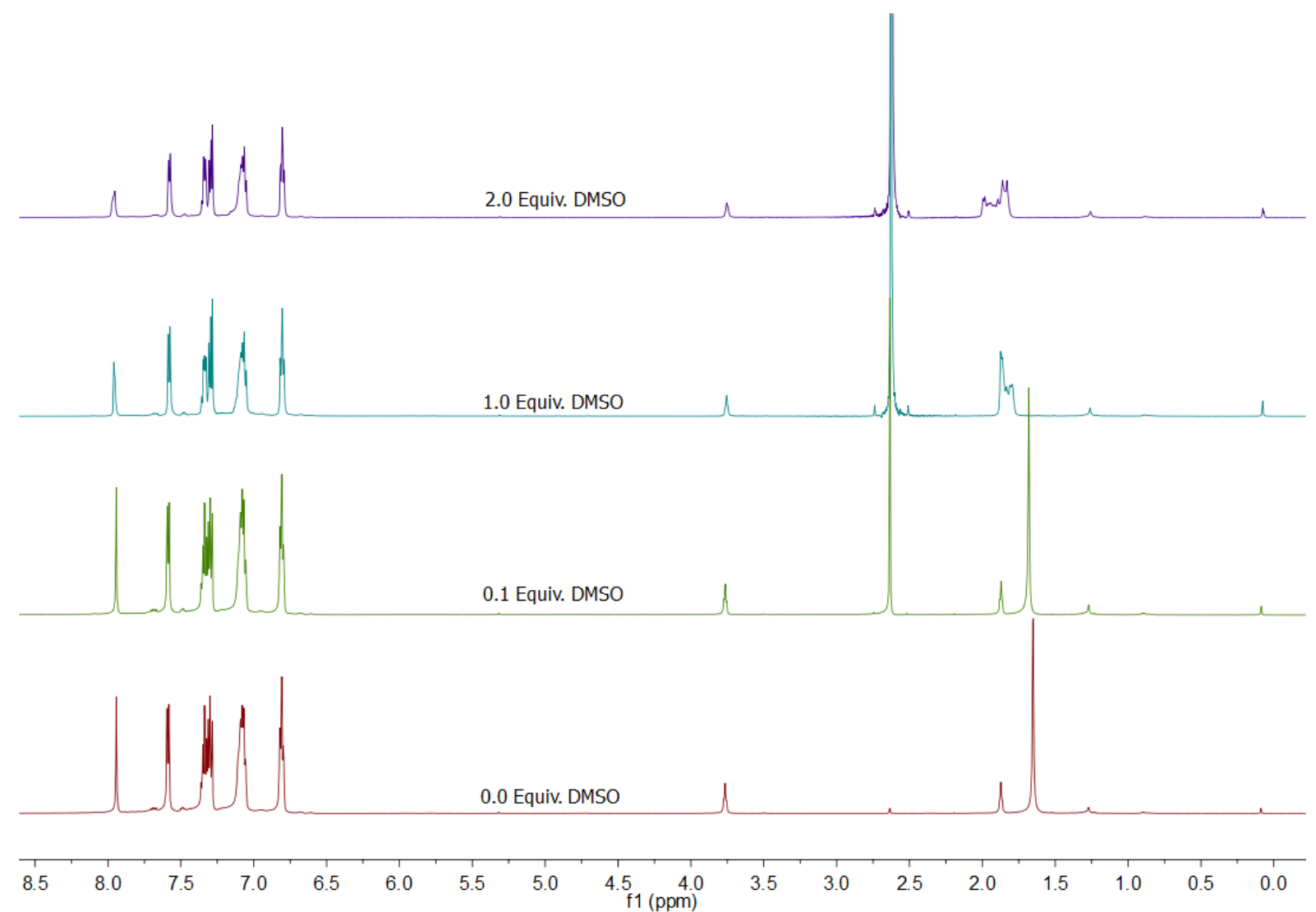

Figure S18: ${ }^{1} \mathrm{H}$ NMR stacked plot of $\mathbf{1 b}$ in $\mathrm{CDCl}_{3}$ with adding various amount of DMSO

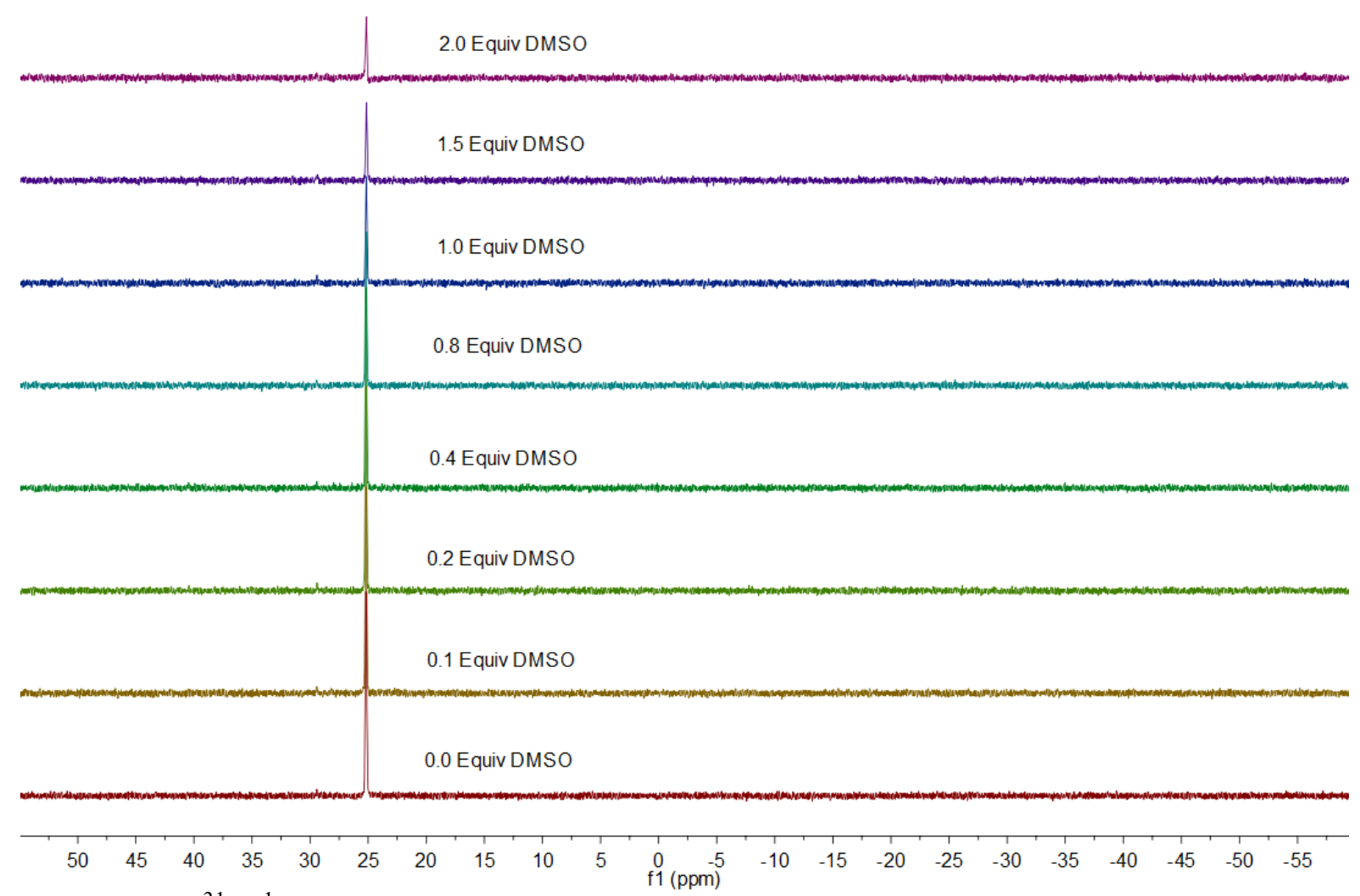

Figure S19: ${ }^{31} \mathrm{P}\left\{{ }^{1} \mathrm{H}\right\}$ NMR stacked plot of $1 \mathbf{d}$ in $\mathrm{CDCl}_{3}$ with adding various amount of DMSO 


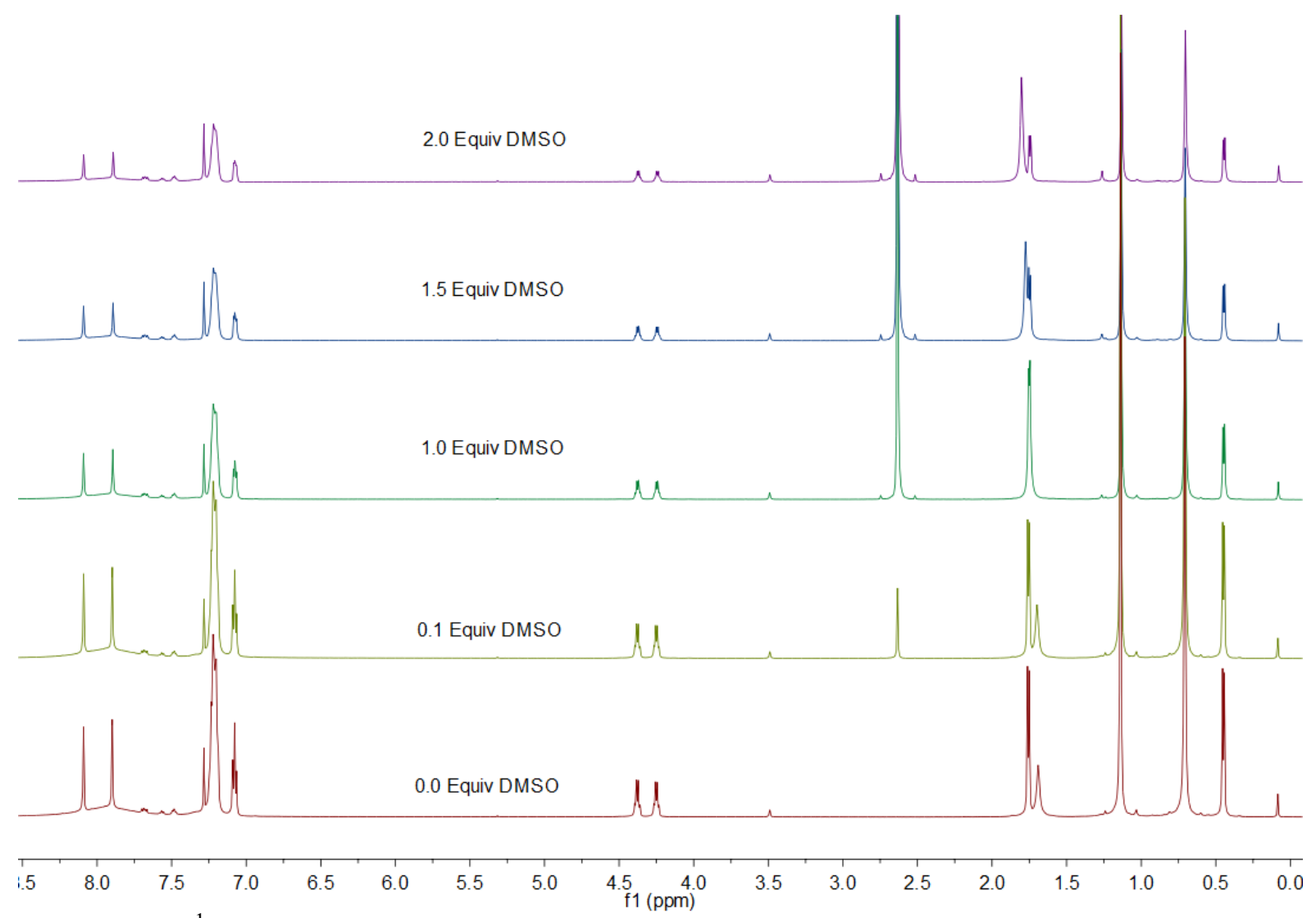

Figure S20: ${ }^{1} \mathrm{H}$ NMR stacked plot of $\mathbf{1 d}$ in $\mathrm{CDCl}_{3}$ with adding various amount of DMSO

\section{UV-Visible spectra}

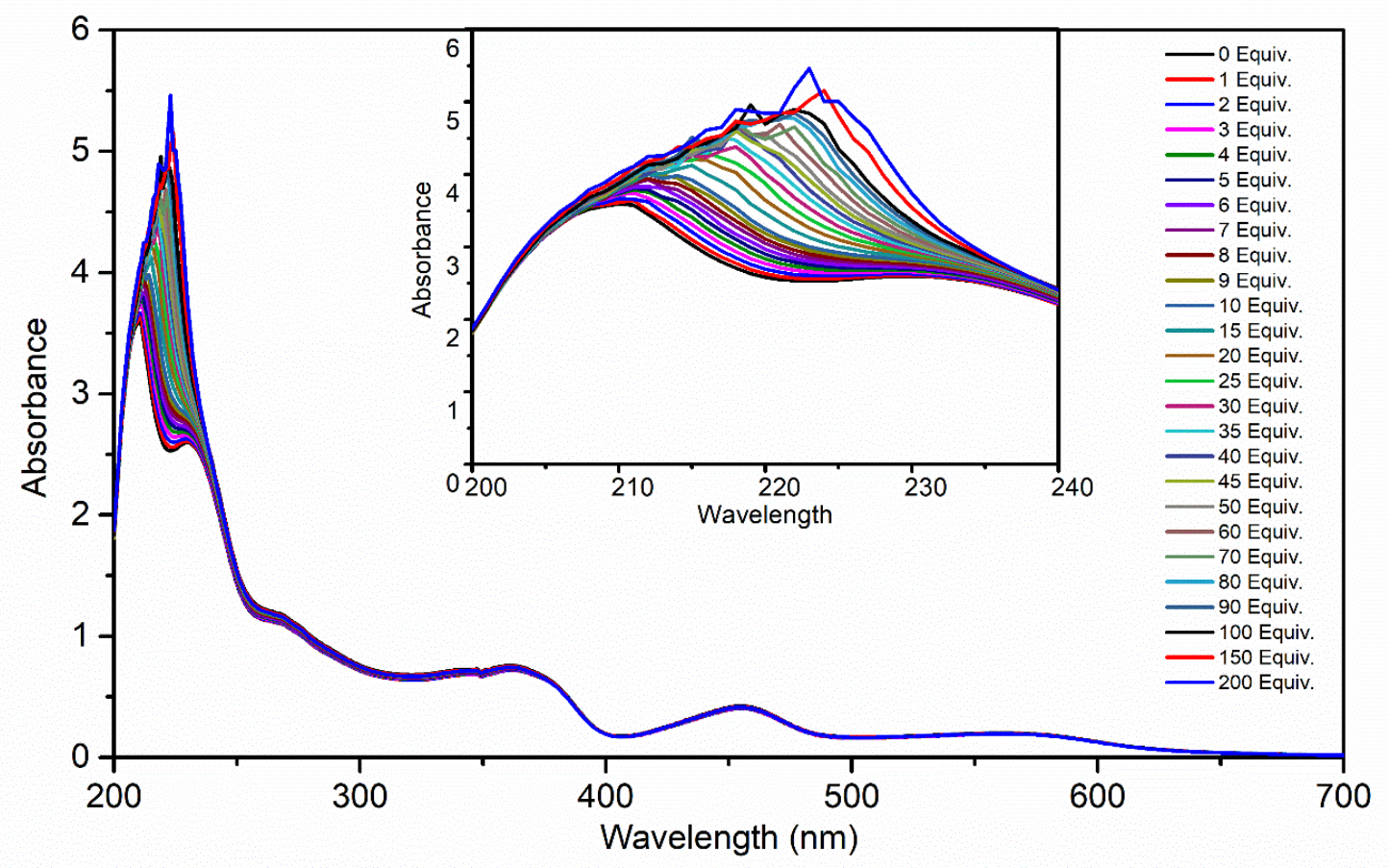

Figure S21: UV-Vis spectrum of $\mathbf{1 a}$ in methanol with gradient addition of DMSO 


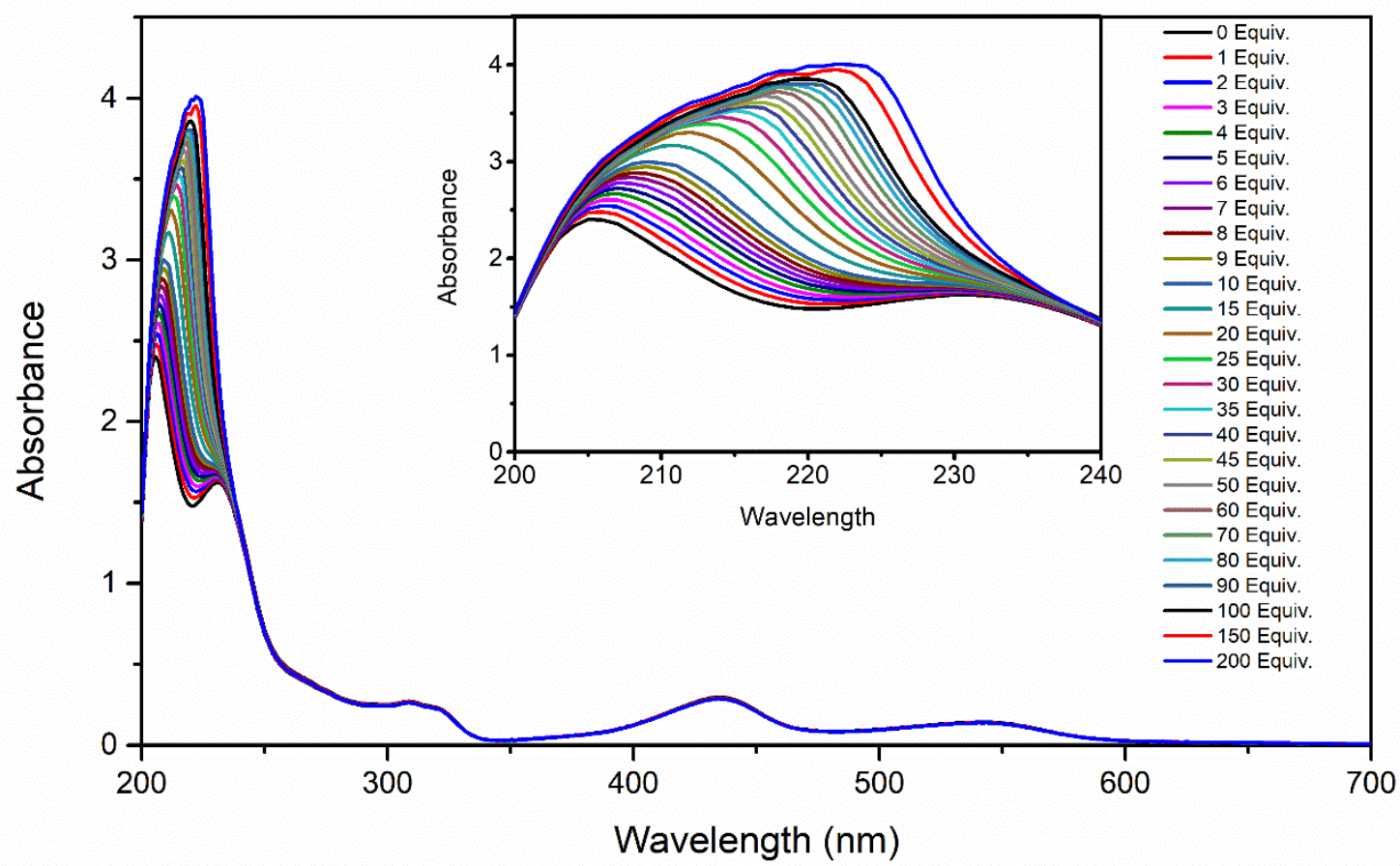

Figure S22: UV-Vis spectrum of $\mathbf{1 b}$ in methanol with gradient addition of DMSO

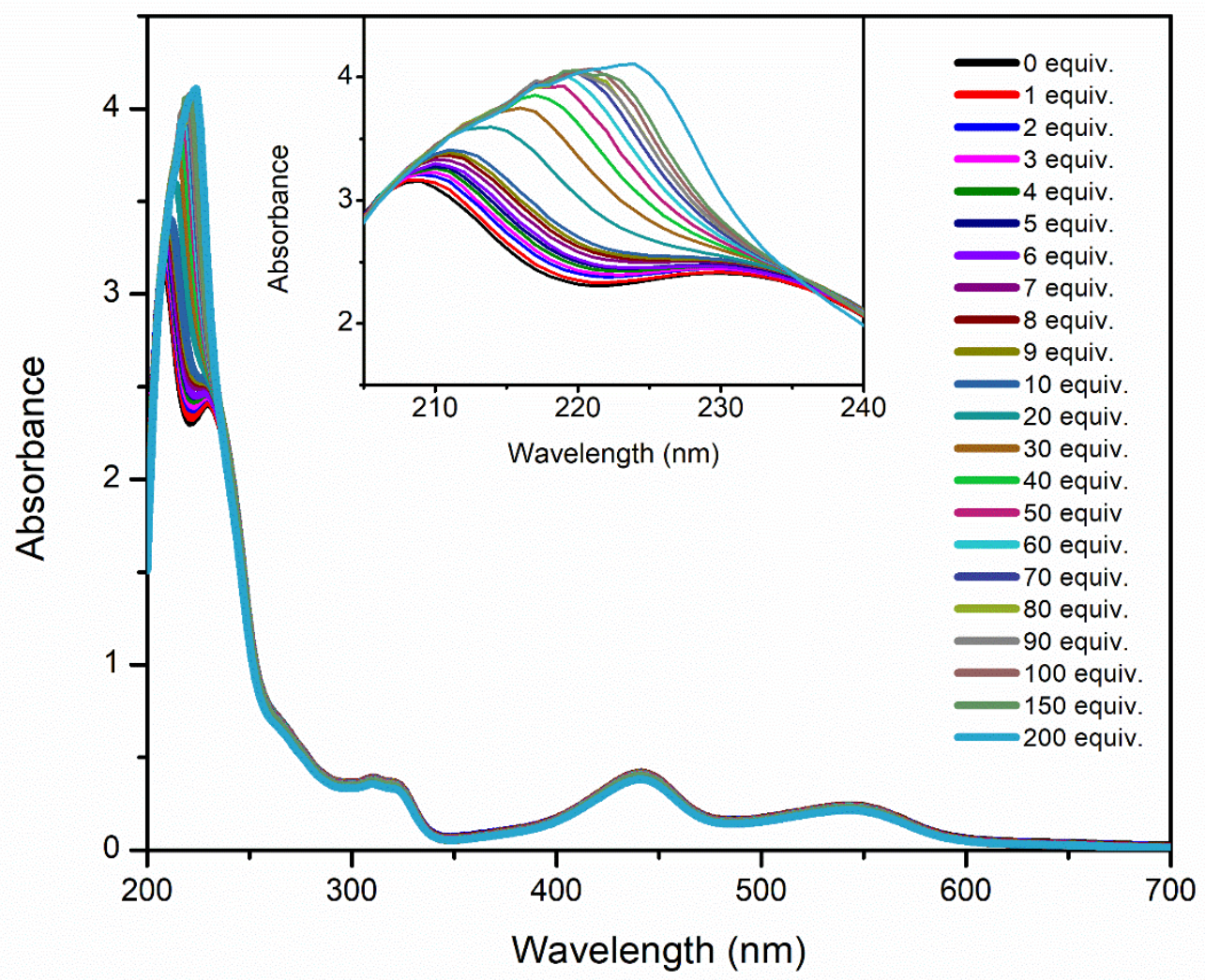

Figure S23: UV-Vis spectrum of 1d in methanol with gradient addition of DMSO 


\section{Cyclic voltammetry}

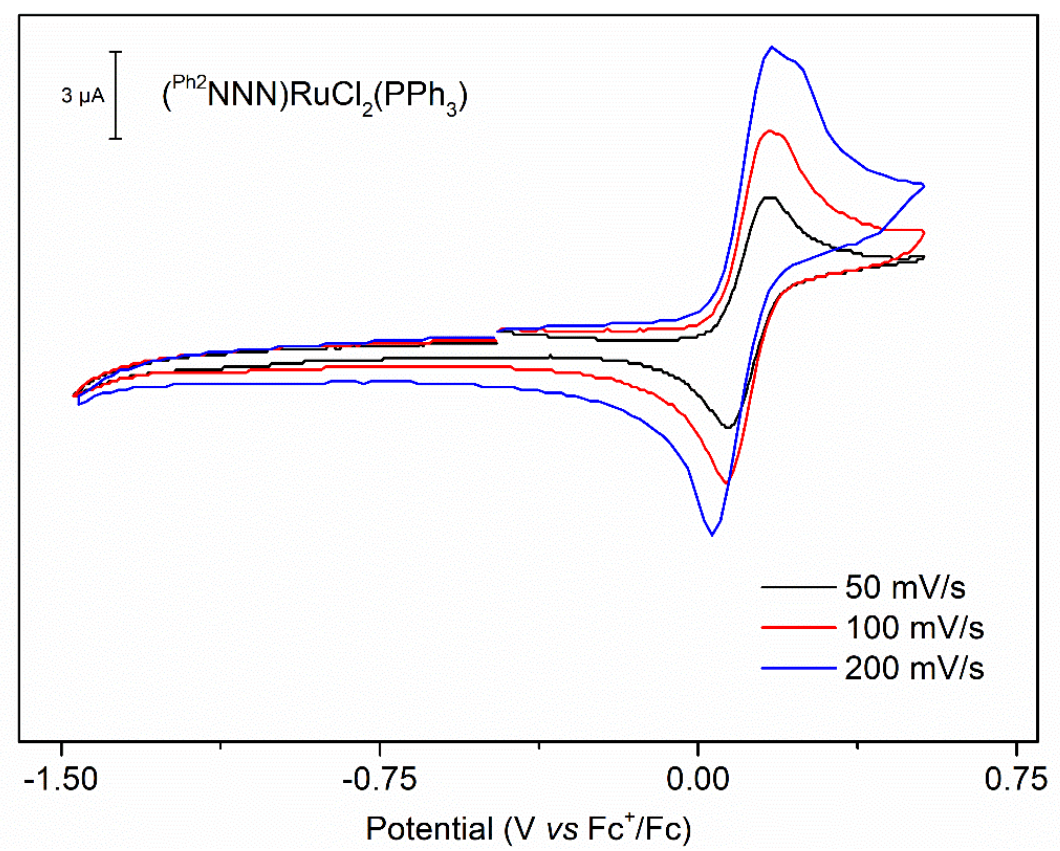

Figure S24: Cyclic voltammogram of 1a in dichloromethane at different scan rates.

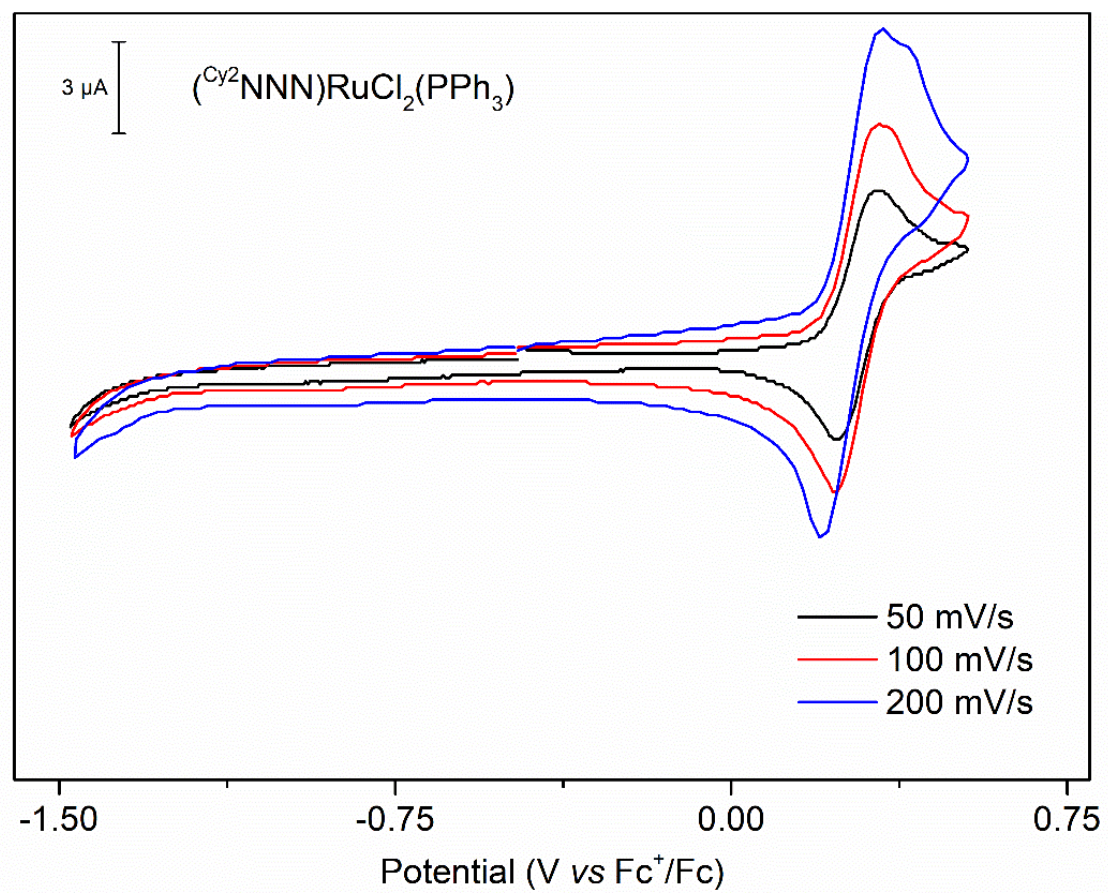

Figure S25: Cyclic voltammogram of $\mathbf{1 b}$ in dichloromethane at different scan rates. 


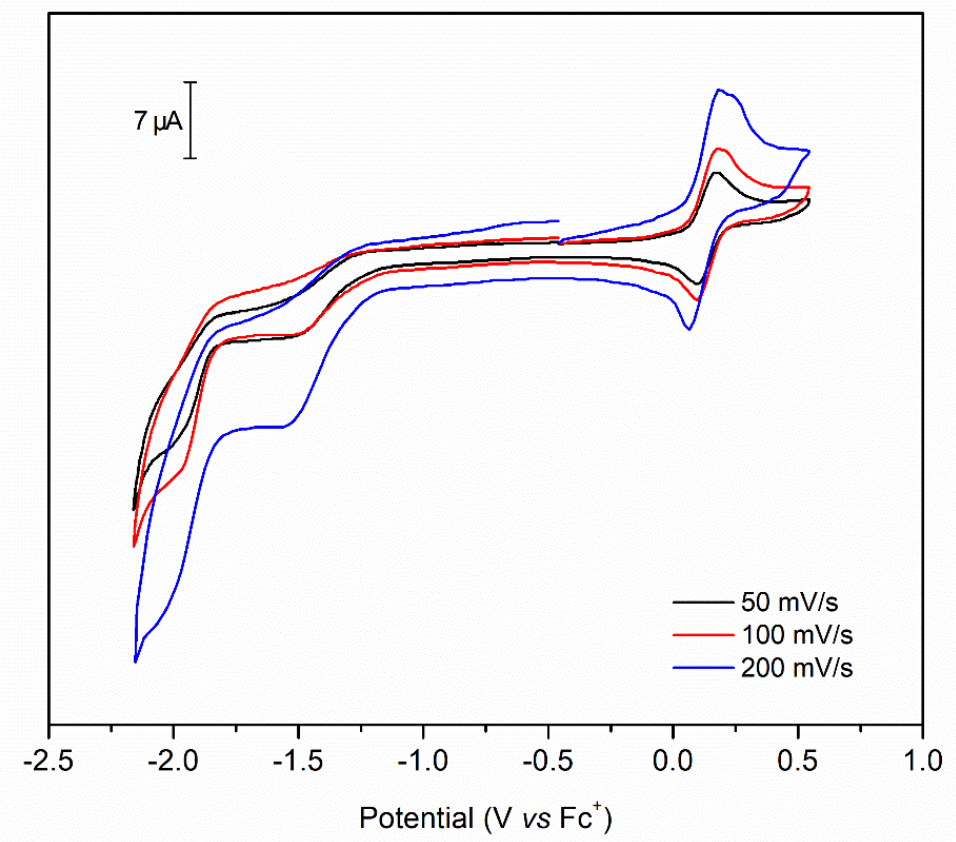

Figure S26: Cyclic voltammogram of 1c in dichloromethane at different scan rates.

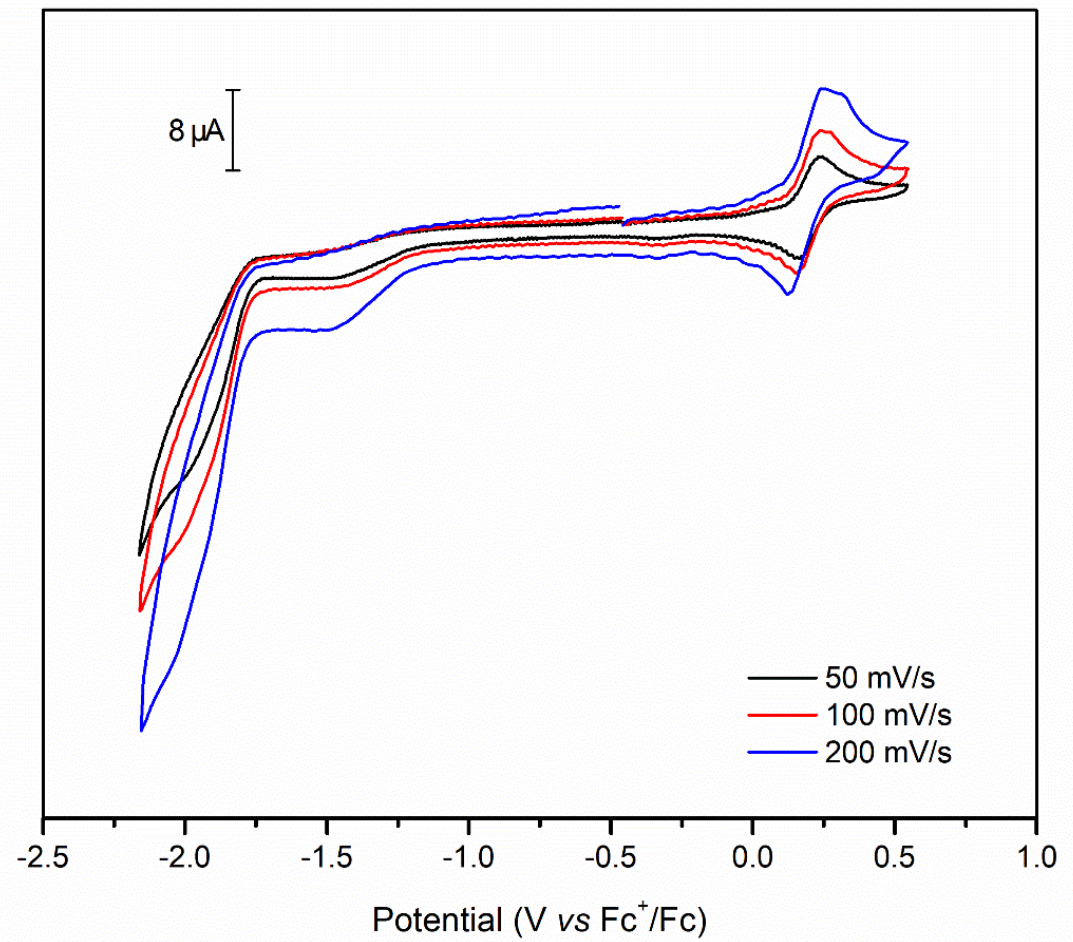

Figure S27: Cyclic voltammogram of 1d in dichloromethane at different scan rates. 


\section{Circular dichroism spectra}

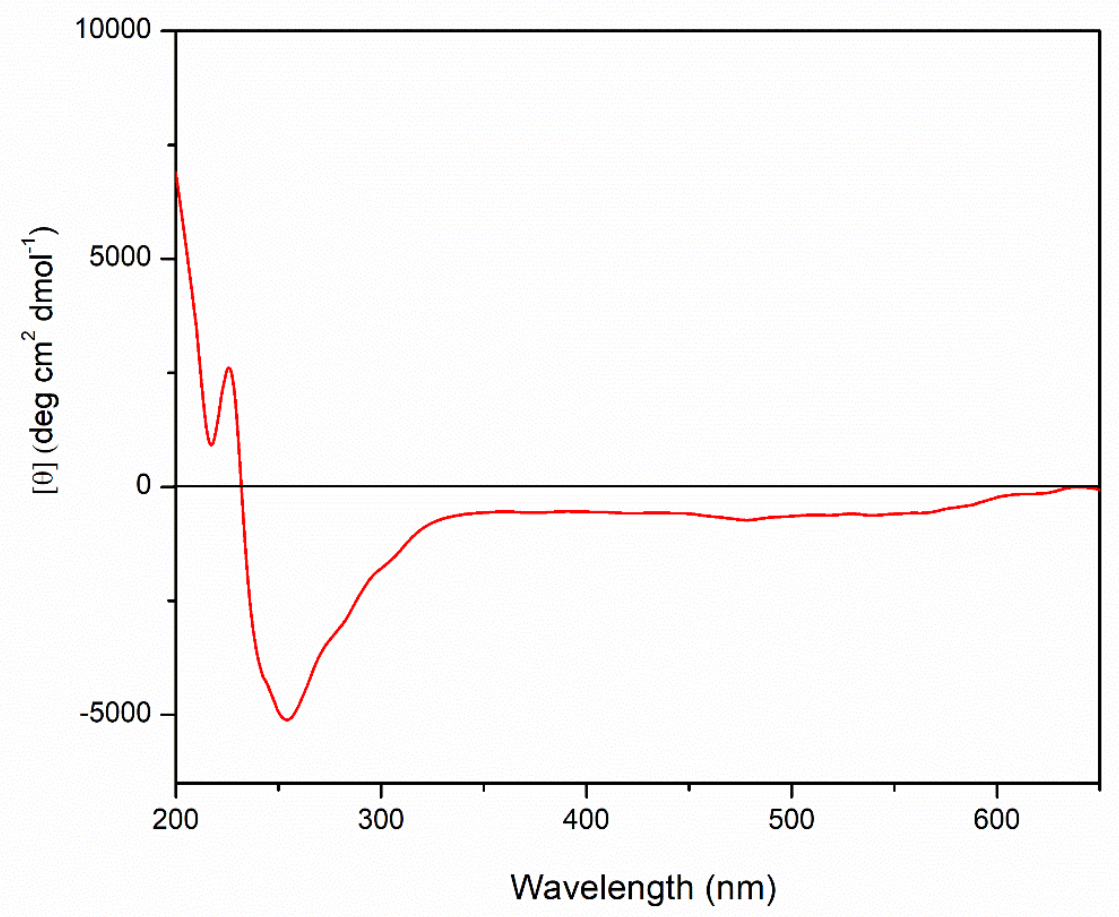

Figure S28: Circular Dichroism (CD) spectra of $\mathbf{4}$ in methanol

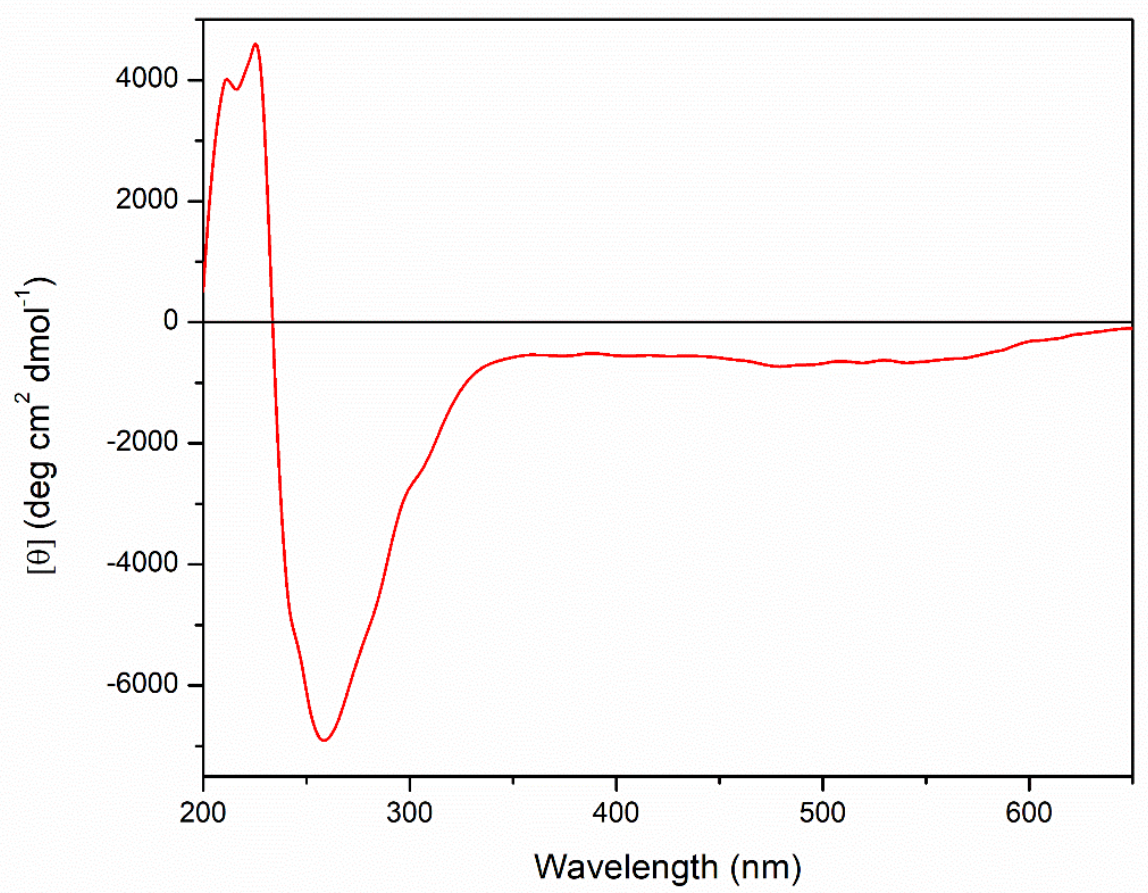

Figure S29: Circular Dichroism (CD) spectra of 6 in methanol 


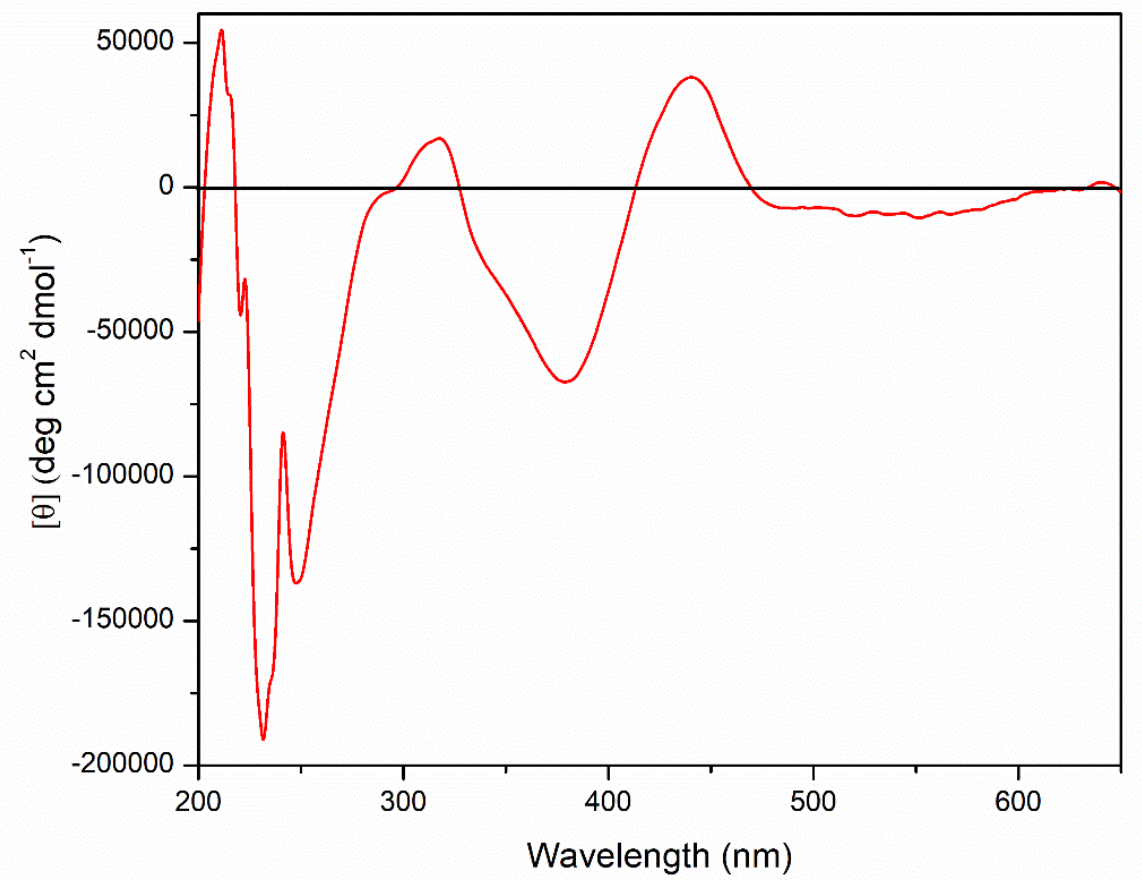

Figure S30 Circular Dichroism (CD) spectra of 1c in methanol

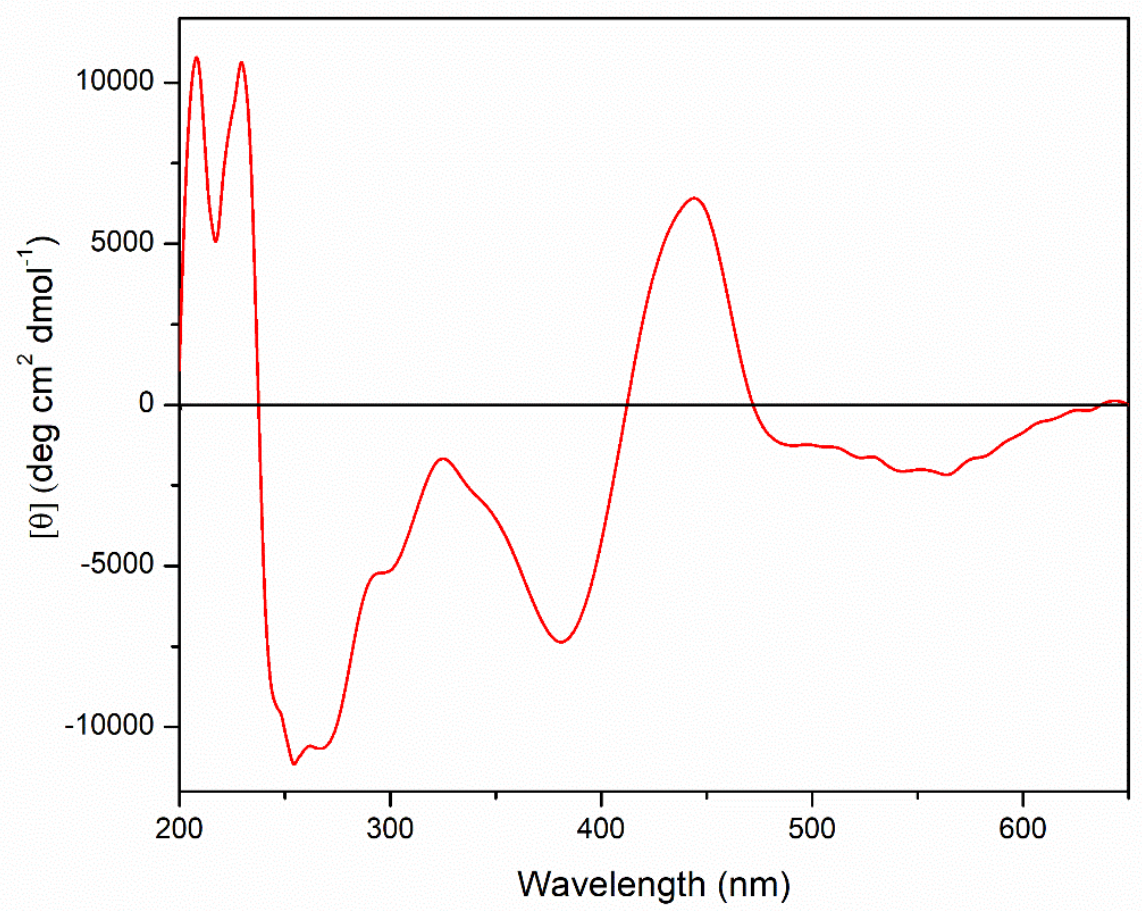

Figure S31: Circular Dichroism (CD) spectra of 1d in methanol 


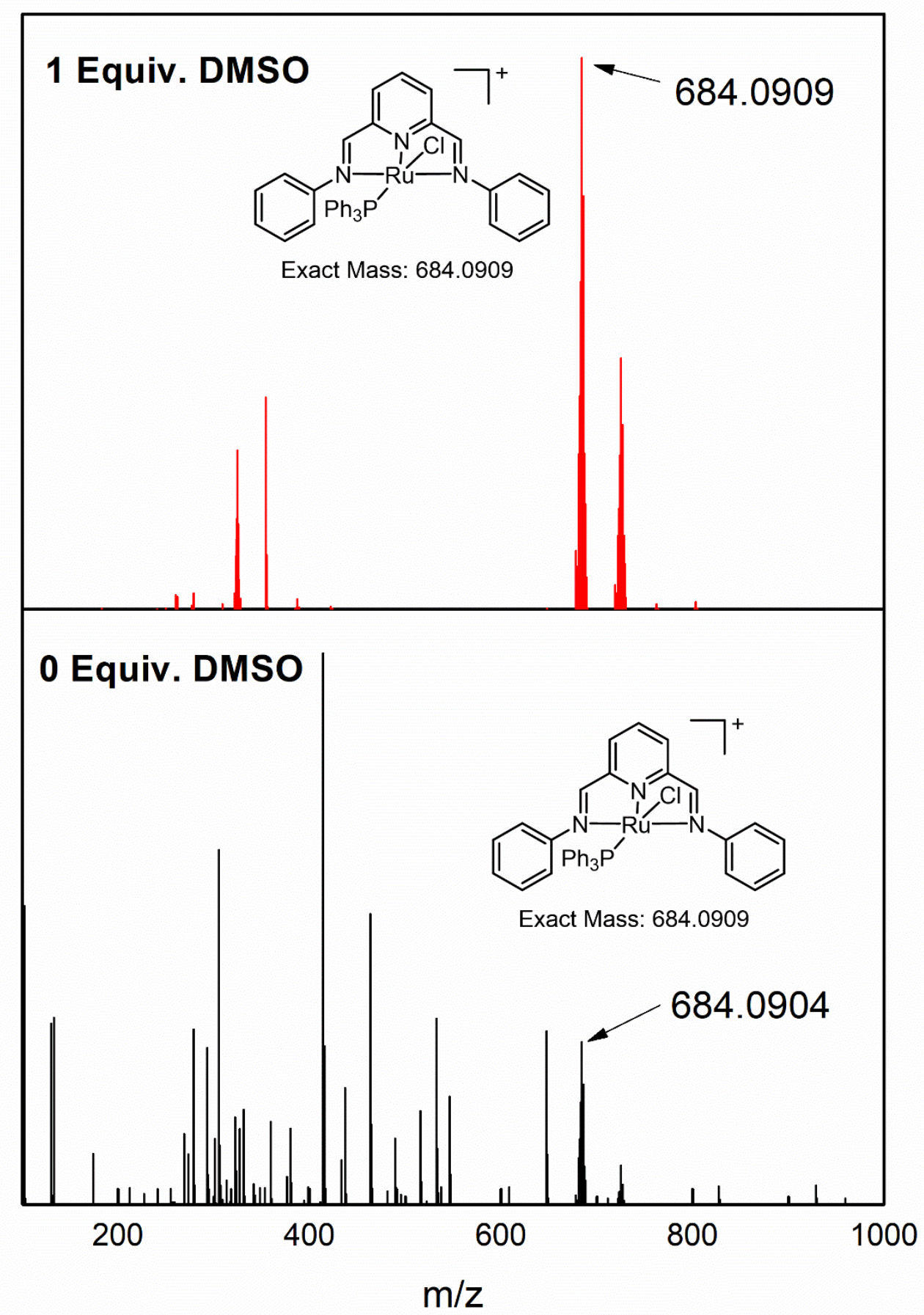

Figure S32: ESI-MS Spectra of 1a in presence and in absence of DMSO in methanol 


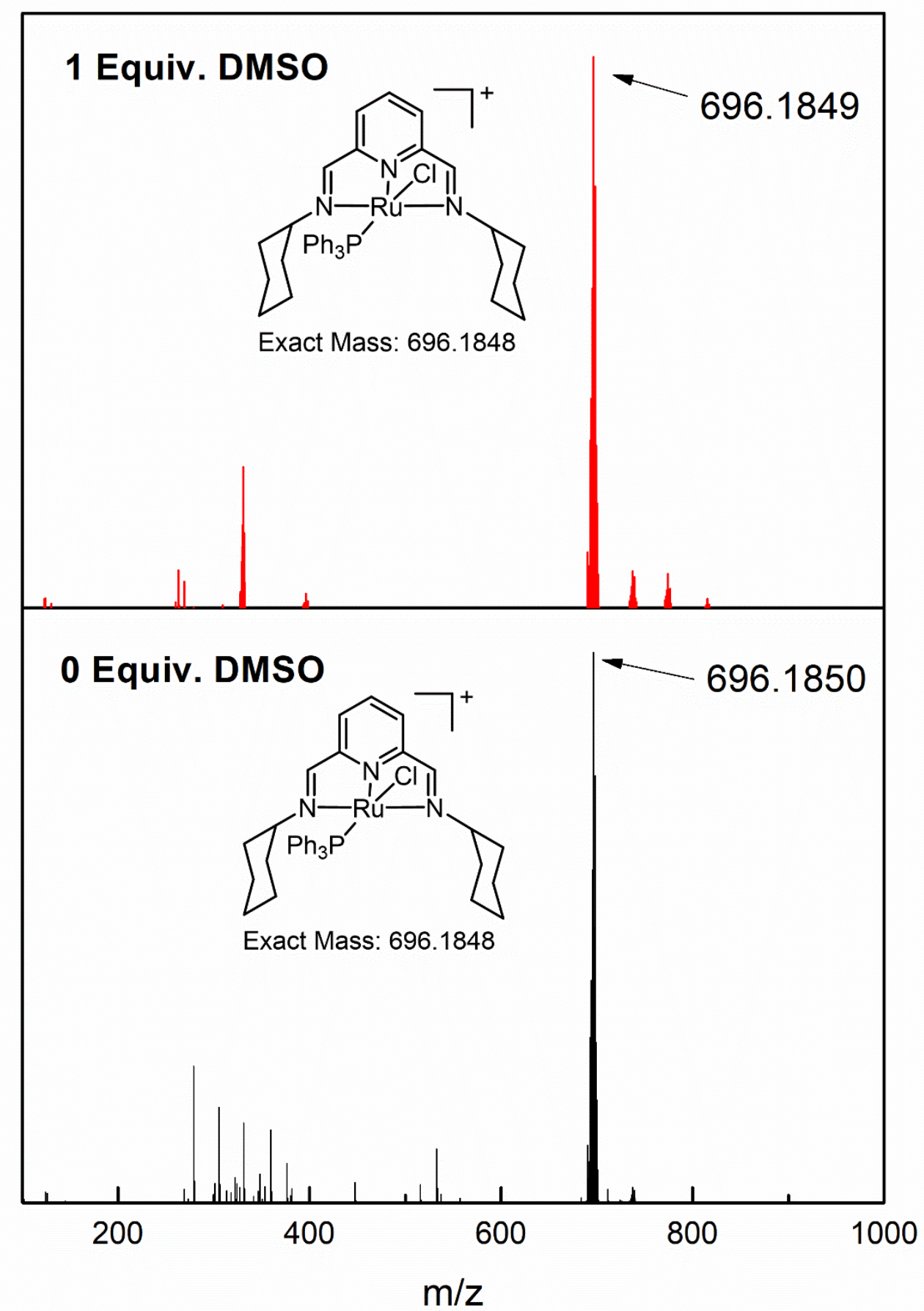

Figure S33: ESI-MS Spectra of $\mathbf{1 b}$ in presence and in absence of DMSO in methanol 


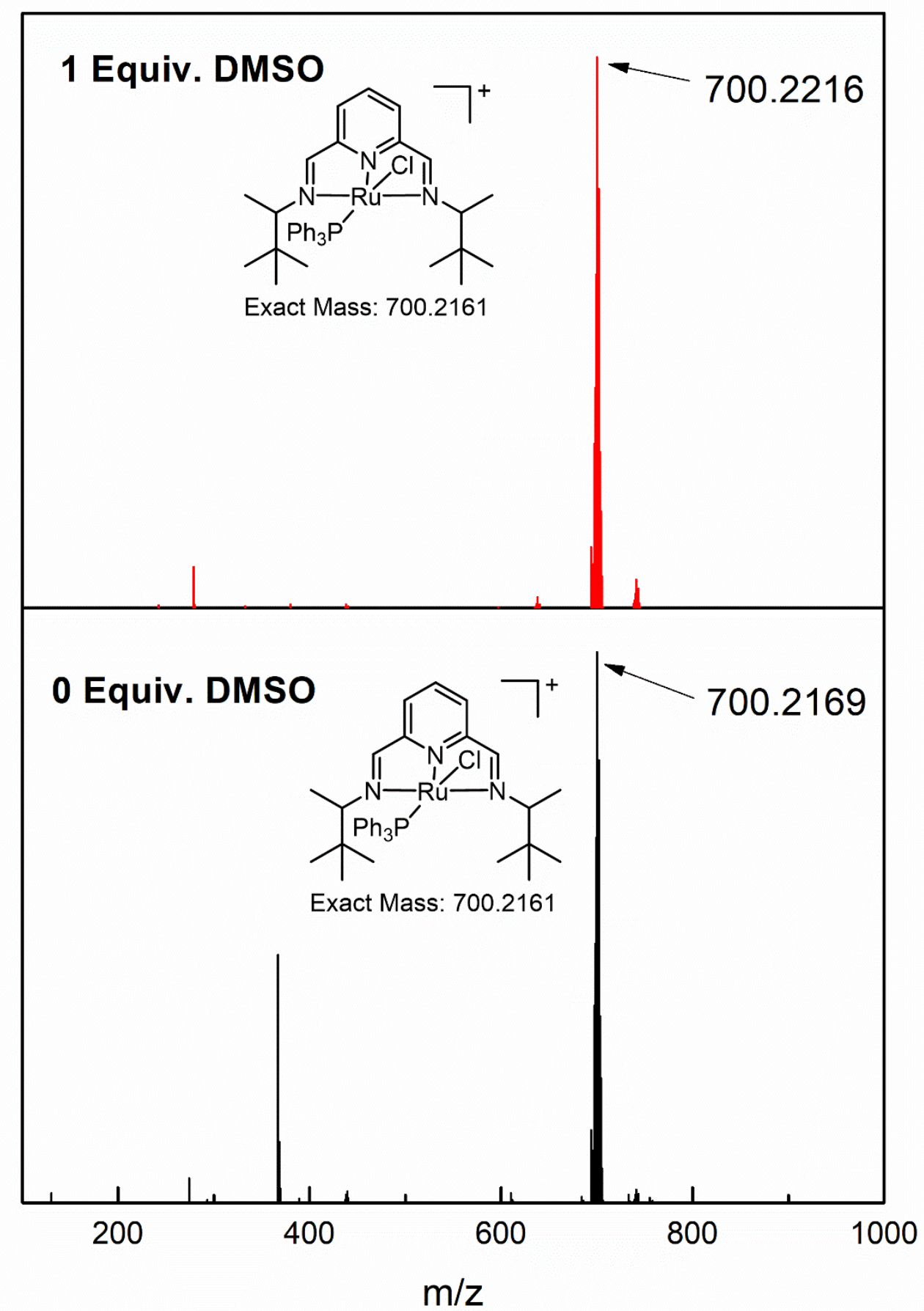

Figure S34: ESI-MS Spectra of 1d in presence and in absence of DMSO in methanol 
7. Fluorescence studies of the complexes in presence of DMSO
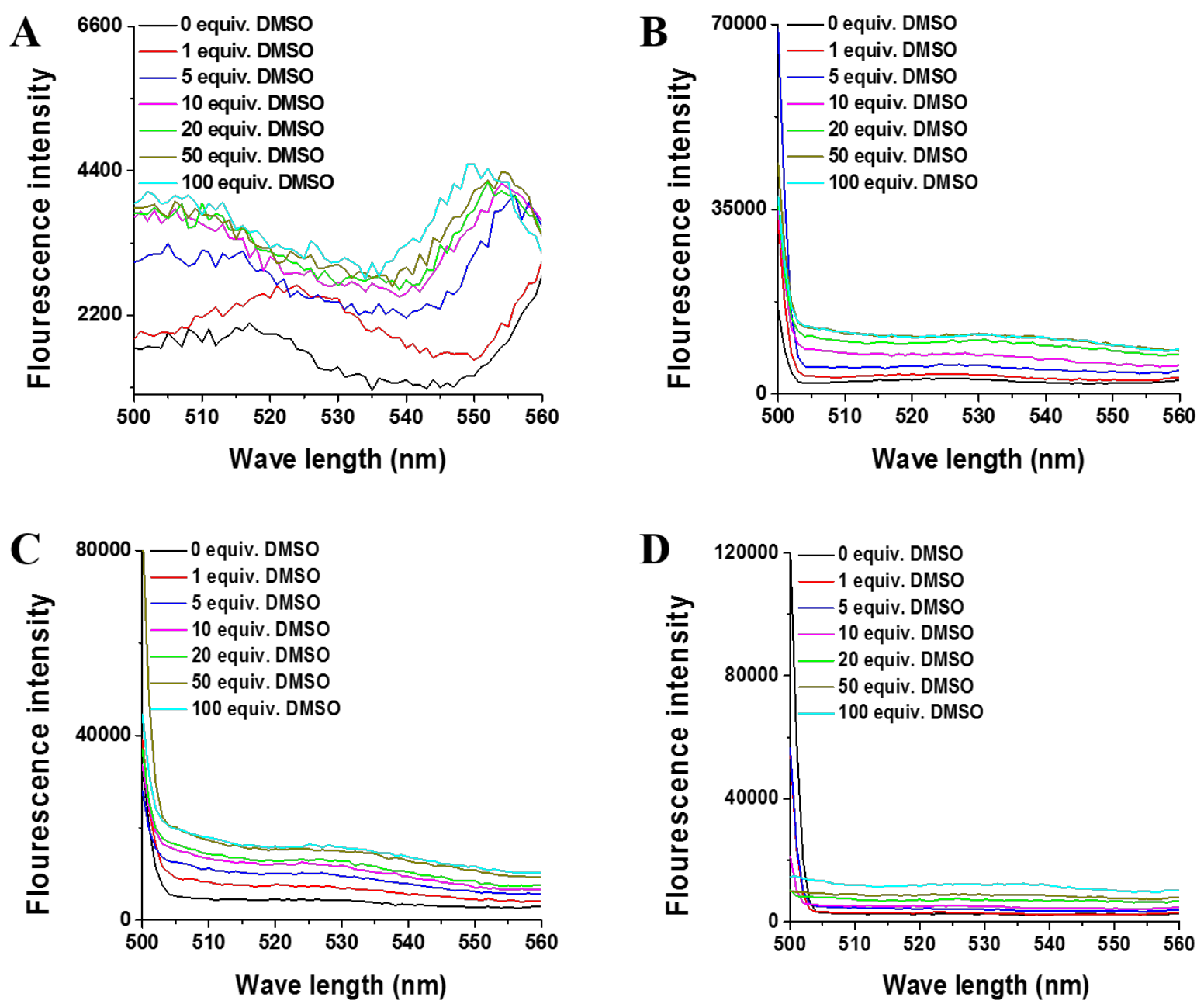

Figure S35: The fluorescence spectral profiles of (A) 1a, (B) 1b, (C) 1c, and (D) 1d complexes in DMSO were recorded from 500-560 $\mathrm{nm}$ when excited at $488 \mathrm{~nm}$. 